\title{
ESTUDIO MERCADOLÓGICO PARA LA REACTIVACIÓN DEL CENTRO ECOTURÍSTICO TZISCAO EN LA TRINITARIA, CHIAPAS
}

\author{
MARKETING STUDY FOR THE REACTIVATION OF THE TZISCAO ECOTOURISTIC \\ CENTER IN LA TRINITARIA, CHIAPAS
}

\author{
Francisco Gabriel Yáñez-Domínguez ${ }^{1}$ * (D); María Lucrecia Novelo-Galindo ${ }^{2}$ (D); \\ Yolanda del Rosario Guillén-Domínguez ${ }^{3}$ (D).
}

1.Tecnológico Nacional de México, Instituto Tecnológico de Comitán. francisco.yd@comitan.tecnm.mx 2.Tecnológico Nacional de México, Instituto Tecnológico de Comitán. maria.ng@comitan.tecnm.mx

3.Tecnológico Nacional de México, Instituto Tecnológico de Comitán. yolanda.gy@comitan.tecnm.mx

*Autor de Correspondencia: Francisco Gabriel Yáñez-Domínguez, correo electrónico:francisco.yd@comitan.tecnm.mx

\section{RESUMEN}

El turismo es un fenómeno muy complejo que involucra diversos aspectos tanto ecológicos, económicos, sociales y culturales, así como diversos actores (turistas, pobladores, autoridades e instituciones) y donde por lo general poca atención se le ha prestado a los aspectos sociales y culturales de dicho fenómeno, es decir que en quienes se ha reparado poco es en los pobladores locales con su historia y sus condiciones sociales y culturales específicas, y quienes en última instancia son los que le dan concreción al planteamiento teórico. La necesidad de desarrollar el presente estudio mercadológico nace por la necesidad de aumentar la afluencia turística a los centros eco turísticos del municipio de La Trinitaria ya que estos cuentan con una gran riqueza ambiental, para conocer mejor el potencial y generar estrategias de mercado se plantea una metodología descriptiva para identificar los factores clave de éxito de los centros, la cual fue apoyado por una colectada de información con trabajo de campo, realizando esto 4 de los principales centros eco turísticos del municipio señalado con la final de obtener resultados en la definición de estrategias que le ayudaran a que sean más competitivos y obtengas beneficios económicos provenientes del incremento de la demanda turística.

Palabras clave: Ecoturismo; estudio mercadológico; reactivación económica.

Cómo citar:

Yáñez-Domínguez, Francisco Gabriel; Novelo-Galindo, María Lucrecia; Guillén-Domínguez, Yolanda del Rosario. (2021). ESTUDIO MERCADOLÓGICO PARA LA REACTIVACIÓN DEL CENTRO ECOTURÍSTICO TZISCAO EN LA TRINITARIA, CHIAPAS. Revista de Investigaciones Universidad del Quindio, 33(S1), 126-151. https://doi.org/10.33975/riuq. vol33nS1.488 


\begin{abstract}
Tourism is a very complex phenomenon that involves various ecological, economic, social and cultural aspects, as well as various actors (tourists, residents, authorities and institutions) and where generally little attention has been paid to social and cultural aspects. of this phenomenon, that is to say that the people who have been little noticed are the local people with their history and their specific social and cultural conditions, and who are ultimately the ones who give concreteness to the theoretical approach. The need to develop this marketing study arises from the need to increase the tourist influx to the ecotourist centers of the municipality of La Trinitaria since they have a great environmental wealth, to better understand the potential and generate market strategies, a descriptive methodology to identify the key success factors of the centers, which was supported by a collection of information with field work, doing this 4 of the main eco-tourist centers of the indicated municipality with the end of obtaining results in the definition of strategies That will help you to be more competitive and obtain economic benefits from the increase in tourist demand.
\end{abstract}

Keywords: ecotourism, market study, economic reactivation.

\title{
INTRODUCCIÓN
}

Analizar un tema como el turismo es un planteamiento que desde los diversos grupos de poder como el político y el financiero contiene una visión desarrollista, es decir, que se plantea como la opción para un mejoramiento de las condiciones de vida de las personas, donde a lo que se le da prioridad es a lo económico, propiciando con esto, pasar (la mayor de las veces) por alto o por sobre los elementos sociales y culturales de las poblaciones.

El presente documento recoge una amplia recopilación de los resultados y procesos de una exhaustiva investigación que inicia por elaborar un plan mercadológico para reactivar el turismo en municipio de La Trinitaria Chiapas, entre los cuales se ha centrado el estudio en el Centro eco turístico Tziscao, de acuerdo al Ayuntamiento municipal de La Trinitaria es el centro con mayor potencial.

Posterior a su evolución se realiza un análisis interno y externo del centro para determinar las fortalezas, debilidades, amenazas y oportunidades y estudiar la relación e impacto que tienen entre ellas con el propósito de comenzar a identificar los factores más relevantes, contabilizar los servicios y capacidad que ofrece es primordial pues permitirá conocer qué y cuanta capacidad tiene el centro para brindar un servicio de calidad, por otro lado se considerara la opinión de los turistas y visitantes pues son el principal objetivo, conocer sus necesidades, sus ideas y opiniones ayudará a establecer el perfil de los visitantes y aportarán información que se usará posteriormente para mejorar cada centro y atraerlos. Consecutivamente a todo el análisis exhaustivo se reflejan los resultados obtenidos de cada método de aplicación permitiendo proponer las estrategias que guiara a la reactivación del centro logrando la misión y visión planteadas al principio del proyecto.

\section{MARCO TEÓRICO}

La planificación estratégica de mercado aplicada al sector turístico tiene un gran valor en el desarrollo de los destinos turísticos, ya que permite una gestión racional de los recursos evitando desequilibrios 
y preservando la sostenibilidad.

De acuerdo Ginesa Martínez, la esencia se ha encontrado en la base de su concepto estratégico, que es consenso de los agentes implicados, a la que se añade creatividad de ideas, flexibilidad, corresponsabilidad con el desarrollo económico del territorio y el uso de la gestión inteligente e innovadora de los destinos. Igualmente, y como indica (Velasco, 2016), la planificación ha alcanzado el crecimiento y el desarrollo del turismo y persigue unos objetivos económicos, espaciales y sociales de gran valor que deben ser considerados. A ello se une la importancia de considerar los planes como "organismos vivos", donde constantemente se deben aportar las acciones y su prioridad, así como rendir cuentas sobre el grado de cumplimiento de los objetivos planteados, para ello el proceso que tiene que llevarse a cabo en el plan estratégico debe estar representada en; Organización y preparación del plan, investigación y análisis, diagnóstico, formulación de propuestas, objetivos, estrategias genéricas y específicas, actuaciones, seguimiento y control de ejecución, (Vas, 2017).

Se observa, igualmente, que la planificación estratégica tiene un carácter orientado más al marketing que a contenidos territoriales (Vera, López Palomeque, \& Marchena, 2011). Por ello el propósito de este método es saber planificar, regular y evaluar la situación actual del proyecto a trabajar, alcanzar y cumplir con los objetivos que se plantearon al principio, sabiendo ejecutar estrategias acordes a las situaciones evaluadas durante todo el estudio.

Para realizar un estudio profundizado el plan estratégico debe estar aunado a herramientas que ayudarán recaudar información precisa y concisa, al mismo tiempo esta información será desmenuzada y analizada para dar soluciones y encontrar estrategias contundentes.

El inventario es el registro de los bienes que pertenecen a una persona natural o jurídica. Así, queda constancia de una serie de activos u objetos. Es decir, el inventario en términos generales es un documento donde se anotan todas las pertenencias del individuo o sector. Esto con fines contables o de otra naturaleza

La importancia del inventario en este caso es una herramienta bastante útil porque permite a cada uno de los centros planificarse en sus actividades y mantener siempre un stock, por decirle así a los servicios disponibles. De este modo se podrá satisfacer la demanda de los turistas y visitantes. Asimismo, realizar un inventario de forma periódica permitirá identificar si los registros contables coinciden con el inventario físico el cual consta de un conteo totalmente manual como se ve expresado en las siguientes tablas.

Como se ha mencionado en el apartado anterior el plan estratégico para el sector turístico se ha enfocado en la mercadotecnia, pero también debe ser planteado para el crecimiento y desarrollo conforme a las nuevas tendencias tecnológicas como en servicios innovadores. La innovación en el turismo se encuadra dentro del sector de servicios (Haudnes, 1998). El turismo es un sector que está sometido a un constante proceso de innovación, debido a que al ser unos servicios que tienen que proporcionar emociones nuevas a los turistas, si no innovan las actividades se convierten en rutinarias y dejan de proporcionar emociones y de ser visitadas (Plog, 1974,) por ello es que varios centros se han dado a la tarea de ir mejorando e implementado en actividades completamente nuevas para hacerlas atractivas. Cuando el turista visita un lugar ha de sentir emoción en cada uno de los componentes de su viaje -servicios- como en el producto turístico que se le ofrece en su conjunto. Las innovaciones pueden ser de distinto tipo según el parámetro desde el que partamos. En base al grado pueden ser radicales 
o incrementales y según el factor de innovación pueden ser de producto, de proceso, de mercado u organizacionales (Antón Álvarez Sousa, 2008).

\section{MÉTODO}

\section{CONOCIMIENTO DE LA HISTORIA Y LA EVOLUCIÓN DE LOS CENTROS ECOTURÍSTICO EN LA TRINITARIA, CHIAPAS.}

De vital importancia para la definición de una estrategia de mercado es conocer los orígenes que sustentan el producto turístico a ofertar.

\section{ANÁLISIS DEL ENTORNO (OPORTUNIDADES Y AMENAZAS)}

Con el análisis externo se pretende obtener resultados que permitan identificar tanto amenazas potenciales, como oportunidades. Por tanto, resulta fundamental analizar todos estos factores con la finalidad de tener un conocimiento exhaustivo de aquellos aspectos relacionados con las amenazas del sector turístico que debe tener en cuenta y las oportunidades que se debe aprovechar.

\section{ANÁLISIS INTERNO (DEBILIDADES Y FORTALEZAS)}

Aquí se identificarán las fortalezas y debilidades del sector turístico en el municipio de La Trinitaria. Las fortalezas son las capacidades del centro y se deben utilizar para su desarrollo y las debilidades son las limitaciones que presenta y es necesario identificarlas para poder trabajar en ellas. Este análisis sirve para identificar las ventajas competitivas, es decir, lo que ofrece el destino de forma diferenciada lo que marca su atractivo en relación con sus competidores, entonces se procederá a realizar una investigación de campo, para ver la situación, que tiene y que se le puede sacar para aprovechar la riqueza de este Centro Ecoturístico, con el fin de promover nuevas ideas para la explotación y ofrecer mejores experiencias a los visitantes.

\section{INVENTARIO}

Se visitará al centro eco turístico para poder conversar con los encargados y ellos mismo nos brinden la información de los servicios que ofrecen al turista, esto será con el fin que se tenga conocimiento que mejoras se puede generar, en caso de no tener algún servicio que sea fundamental incluir para ofrecer al turista.

\section{ELABORACIÓN DE MATRICES}

$\mathrm{Su}$ propósito central es identificar las estrategias para aprovechar las oportunidades externas, contrarrestar las amenazas, acumular y proteger las fortalezas del centro analizados, y erradicar las debilidades. De manera más general, el propósito de un análisis FODA es crear, reforzar o perfeccionar un modelo que intensifique, adecue o combine mejor sus recursos y capacidades con las demandas del ambiente en el que opera.

Fortalezas: Todos aquellos elementos positivos o que fortalecen, provienen del interior del sector.

Oportunidades: Aquellas posibilidades que le ofrece el medio donde se desenvuelve 
Debilidades: Aspectos negativos que debilitan la idea, se originan al interior del sector.

Amenazas: Situaciones que dificultan o amenazan el éxito, provienen del entorno.

Ya que cada centro será analizado debidamente, una vez analizada la situación en la que se encuentra cada centro Ecoturístico se presentara la información en una matriz FODA que se elaborara para mayor compresión en el siguiente capítulo.

\section{DISEÑO DE OBJETIVOS Y ESTRATEGIA DE MERCADO}

A la vista del análisis realizado, se desprenderá que las estrategias a adoptar son por un lado de reorientación, es lo mismo combinas las oportunidades de futuro con las debilidades presentes e intentar con ello corregir carencias del centro eco turístico, también aprovecharía las fortalezas del presente para obtener las oportunidades de futuro, intentando obtener el máximo partido de la situación favorable del entorno.

Se cuantificara cada factor en una tabla con todas las variables a estudiar, se suman los resultados totales y se obtiene información muy valiosa sobre qué cuadrante hay que prestar más atención, cuales son los factores a tener en cuenta más importantes y qué estrategias debe realizar la empresa para potenciar unos y evitar otros.

\section{REALIZACIÓN DE UNA ENCUESTA}

Una encuesta es un estudio que nos permitirá conocer los aspectos de mayor importancia, en éste caso será identificar el grado de satisfacción durante su estancia de los turistas y visitantes que llegan al Centro Ecoturístico.

\section{ANÁLISIS DE LAS ENCUESTAS REALIZADAS}

Una vez aplicada la encuesta se procede al análisis de las mismas del cual se desprende el punto siguiente.

\section{ELABORACIÓN DE PROPUESTAS}

Resultado de lo anterior, al conocer lo hallazgos, se procederá a hacer una serie de planteamientos para que tanto autoridades como los propios encargados del centro eco turístico puedan establecer medidas que permitan su rápida reactivación económica.

\section{HALLAZGOS}

\section{HISTORIA Y EVOLUCIÓN DE LOS CENTROS ECOTURÍSTICO DE LA TRINITARIA, CHIAPAS.}

En el municipio de La Trinitaria, aún subsisten vestigios mayas como Chincultik, en tiempos prehispánicos se denominó Zapalúta, el cual era el nombre original, significa en nahoa "Camino de Enanos" y los tojolabales que pueblan hoy, gran parte del territorio le denominan Tierra de Plátanos. En los años de la conquista, soldados de Pedro Portacarrero llegaron a los llanos de Zapaluta, pero 
fueron detenidos por Mazariegos. En 1911, el gobernador Flavio Guillén decreta oficialmente el nombre de La Trinitaria para este municipio, el cual guarda celosamente entre sus joyas turísticas las grutas de San Francisco, la impresionante cima y los Lagos de Montebello ubicado en Tziscao, lleno de excitantes colores. Durante mucho tiempo La Trinitaria fue aduana fronteriza de Comitán sin embargo el 11 de Diciembre de 1882 ya se reconoce a Zapaluta como municipalidad.

El gobernador Flavio Guillén emite el decreto que otorga el nombre de La Trinitaria al municipio y a la ciudad en 1911, en honor a la fiesta de la Trinitaria, tan famosa en la región. El primer presidente que tuvo el ayuntamiento municipal de La Trinitaria fue Felipe Vera en 1874, a partir de ahí se formaron cada uno de las áreas que forman parte del ayuntamiento, entre ellos el departamento de turismo. De acuerdo con información de la Secretaría de Turismo, la infraestructura turística existente en el municipio, en el año 2000 había 1 hotel con 6 habitaciones.

\section{ANÁLISIS EXTERNO}

\begin{tabular}{|c|c|c|}
\hline & \multicolumn{2}{|c|}{ CENTRO ECOTURISTICO TZISCAO } \\
\hline & OPORTUNIDADES & AMENAZAS \\
\hline 1 & Equipamiento hotelero. & Acceso restringido a fuentes de financiamiento. \\
\hline 2 & $\begin{array}{l}\text { Creación de eventos sociales para la } \\
\text { promoción y difusión. }\end{array}$ & Tiene poca inversión. \\
\hline 3 & $\begin{array}{l}\text { Gestionar eventos nacionales e } \\
\text { internacionales de todo tipo para estimular } \\
\text { la visita. }\end{array}$ & $\begin{array}{l}\text { Falta de continuidad en las políticas de } \\
\text { desarrollo turístico debido a cambios de } \\
\text { gobierno y administración. }\end{array}$ \\
\hline 4 & $\begin{array}{l}\text { Se incluye grupos para ver cómo se trabaja } \\
\text { con la naturaleza. }\end{array}$ & $\begin{array}{l}\text { Progresiva pérdida de identidad cultural del } \\
\text { destino. }\end{array}$ \\
\hline 5 & $\begin{array}{l}\text { Entrada de cadenas hoteleras nacionales en } \\
\text { la región. }\end{array}$ & $\begin{array}{l}\text { Por tal razón los visitantes solo vienen un } \\
\text { rato y se van. (Pernotan). }\end{array}$ \\
\hline 6 & Si cuenta con tour-operadoras. & $\begin{array}{l}\text { Escasa alianza con sectores de turismo de } \\
\text { naturaleza.. }\end{array}$ \\
\hline 7 & $\begin{array}{l}\text { Desarrollo de productos de grupos } \\
\text { originarios y comercializados entre centros } \\
\text { turísticos. }\end{array}$ & $\begin{array}{l}\text { Adolece de una marca propia para que sean } \\
\text { reconocidos por su trabajo. }\end{array}$ \\
\hline 8 & $\begin{array}{l}\text { Concientización creciente sobre la } \\
\text { conservación ambiental en la población } \\
\text { local. }\end{array}$ & $\begin{array}{l}\text { Que en ocasiones no todos llevan a cabo la } \\
\text { conservación del manejo de los residuos. }\end{array}$ \\
\hline 9 & $\begin{array}{l}\text { Incremento a nivel nacional del turismo de } \\
\text { naturaleza, cultural y de aventura. }\end{array}$ & $\begin{array}{l}\text { Plan de manejo de capacidad de carga } \\
\text { turística y aprovechamiento inexistente. }\end{array}$ \\
\hline 10 & Riqueza gastronómica. & Nula promoción gastronómica del lugar. \\
\hline
\end{tabular}




\section{ANÁLISIS INTERNO}

\begin{tabular}{|c|c|c|}
\hline \multicolumn{3}{|c|}{ ANÁLISIS INTERNO } \\
\hline & \multicolumn{2}{|c|}{ CENTRO ECOTURISTICO TZISCAO } \\
\hline & FORTALEZA & DEBILIDAD \\
\hline 1 & Alto poder de atracción. & Delimitantes por la norma 133. \\
\hline 2 & $\begin{array}{l}\text { Se encuentra con límite de la república de } \\
\text { Guatemala y México, dentro de la reserva } \\
\text { parque nacional lagunas de Montebello. }\end{array}$ & Poca difusión que ausencia la demanda turística. \\
\hline 3 & Ofrece artesanía de Guatemala. & $\begin{array}{l}\text { Desaprovechamiento de productos y artesanías } \\
\text { turísticas locales. }\end{array}$ \\
\hline 4 & $\begin{array}{l}\text { Senderos y áreas exclusivos para la } \\
\text { investigación de aves. }\end{array}$ & Ubicación geográfica no reconocida. \\
\hline 5 & Sellos distintivos de calidad. & Pago efectuado anualmente para reacreditación. \\
\hline 6 & $\begin{array}{l}\text { Se encuentra ubicado dentro de dos rutas } \\
\text { importantes la Ruta Maya y Ruta Camino } \\
\text { Real. }\end{array}$ & $\begin{array}{l}\text { Tiene poca inversión por agentes que tengan } \\
\text { interés en mejor desarrollo. }\end{array}$ \\
\hline 7 & $\begin{array}{l}\text { Ofrece servicios; paseo a caballo, } \\
\text { senderismo, renta de cayak's. }\end{array}$ & No cuenta con un tour local. \\
\hline 8 & Servicio médico. & Servicio médico muy básico. \\
\hline 9 & $\begin{array}{l}\text { Lanchas fabricadas con alcornoque que son } \\
\text { únicas en el Estado de Chiapas. }\end{array}$ & Escasa difusión de los servicios que ofrece. \\
\hline 10 & Cuenta con el sello Contacto Limpio. & $\begin{array}{l}\text { Incumplimiento con el protocolo que distingue } \\
\text { este sello. }\end{array}$ \\
\hline
\end{tabular}

\section{INVENTARIO DEL CENTRO}

\begin{tabular}{|c|l|c|}
\hline \multicolumn{2}{|c|}{ Centro Ecoturístico Tziscao } & CANTIDAD \\
\hline $\mathbf{N}^{\circ}$ & \multicolumn{1}{|c|}{ Áreas /secciones/ zonas } & No \\
\hline $\mathbf{1}$ & Hotel & 11 \\
\hline $\mathbf{2}$ & Cabañas & $\mathrm{Si}$ \\
\hline $\mathbf{3}$ & Palapas & 1 \\
\hline $\mathbf{4}$ & Área camping & $\mathrm{Si}$ \\
\hline $\mathbf{5}$ & Cocina típica & 7 \\
\hline $\mathbf{6}$ & Restaurant & 1 \\
\hline $\mathbf{7}$ & Sanitarios Públicos & $\mathrm{T}$ \\
\hline
\end{tabular}




\begin{tabular}{|c|c|c|}
\hline 8 & Sala de reuniones & 1 \\
\hline 9 & Guías sin certificación & 80 \\
\hline 10 & Guías certificados & 30 \\
\hline 11 & Servicio telefónico & No tiene \\
\hline 12 & Servicios de internet (Wi-fi) & $\mathrm{Si}$ \\
\hline 13 & Transporte a los Lagos & $\mathrm{Si}$ \\
\hline 14 & Moto taxis turísticos & 10 \\
\hline 15 & Experiencias Turística & $\begin{array}{c}\text { Experiencias en balsas, medicina natural y } \\
\text { ritual maya. }\end{array}$ \\
\hline 16 & Actividades Recreativas & Naturaleza \\
\hline 17 & Recorrido con balsas & 20 \\
\hline 18 & Recorridos con Kayaks & 20 \\
\hline 19 & Recorrido con caballos & No tiene \\
\hline 20 & Recorridos en bicicleta & 2 \\
\hline 21 & Recorrido a la Z.A. & No tiene \\
\hline 22 & Recorrido a las cascadas & No tiene \\
\hline 23 & Senderismo & 2 rutas \\
\hline 24 & Buceo & No tiene \\
\hline 25 & Pesca & $\mathrm{Si}$ \\
\hline 26 & Museo Cultural & 1 \\
\hline 27 & Área para nadar & $\mathrm{Si}$ \\
\hline 28 & Locales con venta de artesanías & $\mathrm{Si}$ \\
\hline 29 & Seguridad municipal o privada las 24 horas & 1 \\
\hline 30 & Área de primeros auxilios & 2 \\
\hline 31 & Salvavidas & No tiene \\
\hline 32 & Recorridos en balsas & 20 \\
\hline
\end{tabular}


Se realizó una lista de control con los servicios que ofrece el centro Eco turístico Tziscao, con el fin de mantener un inventario de que ofrece al turista cuando llega de visitante.

Dentro del centro no cuenta con un hotel que le pertenezca al ejido, pero si cuenta con el servicio de cabañas, de los cuales tienen un total de 11 cabañas que le pertenece al ejido, cuentan con dos cocinas típicas y 7 particulares, en ese mismo centro tienen un sanitario público, además también cuentan con una sala de reuniones que hace poco termino de construirse, este es útil para realizar reuniones ejecutivas.

El centro Ecoturístico tiene servicio de guías que en ocasiones son adquiridos por los turistas para que los acompañen al recorrido, existen 80 guías certificados y 30 guías sin certificación pero que están bastante capacitados para brindar el servicio. Una de los limitantes que existe es que no cuenta con señal de servicio telefónico, pero si tiene el servicio de internet (wi-fi) solo en las cabañas y solo quienes se hospedan adquieren de ese servicio, incluido en el costo total de las cabañas. Los medios de transporte para poder llegar al sitio, son más privados, solo hay una estación que deja al visitante cerca de las lagunas y se debe tomar motoxati para llegar al centro ecoturístico, estos motoxati te cobran $\$ 10$ por persona y son 10 moto taxis los que brindan servicio.

Las experiencias turísticas que ofrece son el recorrido en balsas, la medicina natural y el ritual maya, una actividad recreativa podría ser las actividades de naturaleza. Se cuenta con 20 balsas en cada centro, esta cantidad de balsas solo es en temporada alta, también cuenta con 20 kayaks los cuales están divididos en lago Pojoj, 5 lagos, lago internacional y Montebello.

Aun no cuentan con un área para ofrecer un recorrido a caballo, pero si tiene recorridos en bicicleta. Cabe mencionar que este centro ecoturístico no tiene Zona Arqueológica, ni cascadas.

Para el senderismo aun no tienen rutas marcadas, pero si hay 2 rutas el "perol" y el 2 "Lichair" que están por terminarse de concreto, de igual manera no cuenta con la actividad del buceo porque no hay personal capacitado para esta actividad, ya que la profundidad de las lagunas son de más de 160 metros la pesca solo es controlada y se da más en temporada alta. También tiene un museo cultural que tiene como nombre "liquidámbar" en la cual es representativo de las 10 familias que fundaron Tziscao.

Además tiene locales con venta de artesanías, estas son artesanías de Guatemala, respecto a la seguridad se cierra cadena a partir de las 10 pm y brindan el servicio de primeros auxilios básico, como es un centro de salud, comité de protección civil y equipo de Guarda parques.

\section{ELABORACIÓN DE MATRICES}

\begin{tabular}{|c|c|}
\hline \multicolumn{2}{|c|}{ MATRIZ DAFO } \\
\hline \multicolumn{2}{|c|}{ CENTRO ECOTURÍSTICO TZISCAO } \\
\hline DEBILIDADES & \multicolumn{1}{c|}{ FORTALEZAS } \\
\hline D1. No cuenta con un tour local. & F1. Alto poder de atracción. \\
\hline
\end{tabular}




\begin{tabular}{|c|c|}
\hline $\begin{array}{l}\text { D2. Poca difusión que ausencia la demanda } \\
\text { turística. }\end{array}$ & $\begin{array}{l}\text { F2. Se encuentra con límite de la república de } \\
\text { Guatemala y México, dentro de la reserva parque } \\
\text { Nacional lagunas de Montebello. }\end{array}$ \\
\hline $\begin{array}{l}\text { D3. Desaprovechamiento de productos y } \\
\text { artesanías turísticas locales. }\end{array}$ & F3. Ofrece artesanía de Guatemala. \\
\hline D4. Ubicación geográfica no reconocida. & $\begin{array}{l}\text { F4. Senderos y áreas exclusivos para la } \\
\text { investigación de aves. }\end{array}$ \\
\hline D5. Pago efectual anualmente para recreaditación. & F5. Sellos distintivos de calidad. \\
\hline $\begin{array}{l}\text { D6. Tiene poca inversión por agentes que tengan } \\
\text { interés en mejor desarrollo. }\end{array}$ & $\begin{array}{l}\text { F6. Se encuentra ubicado dentro de dos rutas } \\
\text { importantes la maya y camino real. }\end{array}$ \\
\hline D7. Delimitantes por la norma 133 . & $\begin{array}{l}\text { F7. Ofrece servicios; paseo a caballo, senderismo, } \\
\text { renta de cayak's. }\end{array}$ \\
\hline D8. Servicio médico muy básico. & F8. Servicio médico. \\
\hline D9. Escasa difusión de los servicios que ofrece. & $\begin{array}{l}\text { F9. Lanchas de corcho que son únicos en el } \\
\text { estado. }\end{array}$ \\
\hline $\begin{array}{l}\text { D10. Que no se cumpla con el protocolo que } \\
\text { distingue este sello. }\end{array}$ & F10. Cuenta con el sello contacto limpio. \\
\hline AMENAZAS & OPORTUNIDADES \\
\hline A1. Tiene poca inversión. & O1. Equipamiento hotelero. \\
\hline $\begin{array}{l}\text { A2. Acceso restringido a fuentes de } \\
\text { financiamiento. }\end{array}$ & $\begin{array}{l}\text { O2. Creación de eventos sociales para la } \\
\text { promoción y difusión. }\end{array}$ \\
\hline $\begin{array}{l}\text { A3. Falta de continuidad en las políticas de } \\
\text { desarrollo turístico debido a cambios de gobierno } \\
\text { y administración. }\end{array}$ & $\begin{array}{l}\text { O3. Gestionar eventos nacionales e } \\
\text { internacionales de todo tipo para estimular la } \\
\text { visita. }\end{array}$ \\
\hline $\begin{array}{l}\text { A4. Progresiva pérdida de identidad cultural del } \\
\text { destino. }\end{array}$ & $\begin{array}{l}\text { O4. Se incluye grupos para ver cómo se trabaja } \\
\text { con la naturaleza. }\end{array}$ \\
\hline $\begin{array}{l}\text { A5. Por tal razón los visitantes solo vienen un } \\
\text { rato y se van (pernoctan). }\end{array}$ & $\begin{array}{l}\text { O5. Entrada de cadenas hoteleras nacionales en } \\
\text { la región. }\end{array}$ \\
\hline $\begin{array}{l}\text { A6. No cuenta con alianza con sectores de } \\
\text { turismo de naturaleza. }\end{array}$ & O6. Si cuenta con tour-operadoras. \\
\hline $\begin{array}{l}\text { A7. No contar con una marca propia para que } \\
\text { sean reconocidos por su trabajo. }\end{array}$ & $\begin{array}{l}\text { O7. Desarrollo de productos de grupos originarios } \\
\text { y comercializados entre centros turísticos. }\end{array}$ \\
\hline $\begin{array}{l}\text { A8. Que en ocasiones no todos llevan a cabo la } \\
\text { conservación del manejo de los residuos. }\end{array}$ & $\begin{array}{l}\text { O8. Concientización creciente sobre la } \\
\text { conservación ambiental en la población local. }\end{array}$ \\
\hline $\begin{array}{l}\text { A9. No existe un plan de manejo de capacidad de } \\
\text { carga turística y aprovechamiento. }\end{array}$ & $\begin{array}{l}\text { O9. Incremento a nivel nacional del turismo de } \\
\text { naturaleza, cultural y de aventura. }\end{array}$ \\
\hline A10. Nula promoción gastronómica del lugar. & 010. Riqueza gastronómica. \\
\hline
\end{tabular}




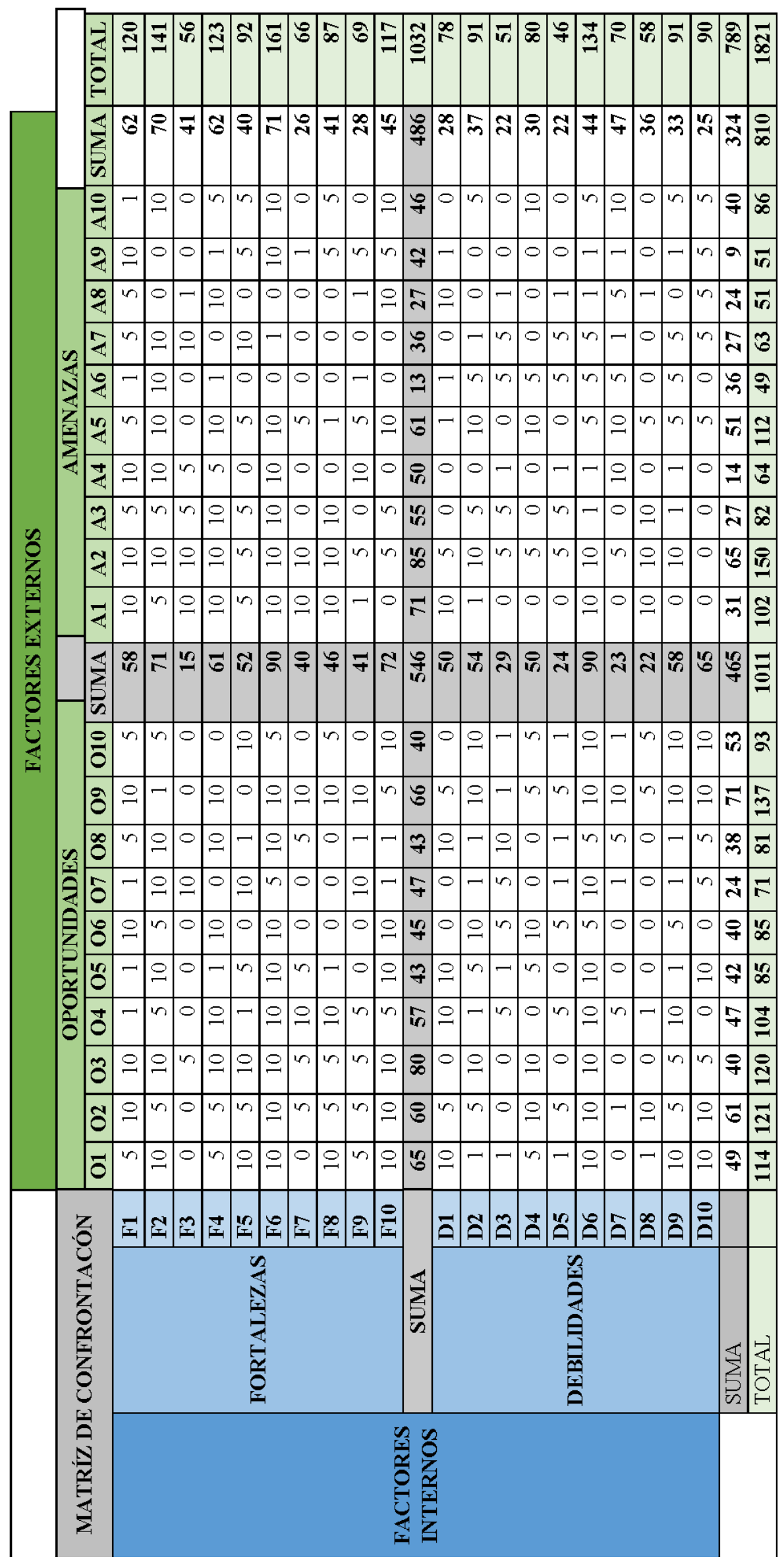




\section{DISEÑO DE OBJETIVOS Y ESTRATEGIAS DE MERCADO}

Una vez elaborada la matriz de confrontación procederemos a analizar la relación entre factores externos e internos el cual es analizado por el cuadrante más valorado

En el centro Ecoturístico de Tziscao acentuando su fortaleza más relevante y es que este (F6) se encuentra ubicado dentro de dos rutas importantes la maya y camino real al aprovechar esta fortaleza nos permite la oportunidad de (03) gestionar eventos nacionales e internacionales de todo tipo para estimular la visita pues estando dentro de dos rutas tan importantes le permiten al centro un gran reconocimiento y competitividad.

Al superar la debilidad más valorada en el que encontramos que el centro (D6) tiene poca inversión por agentes que tengan interés en mejorar el desarrollo turístico, el efecto de esta situación seria el (O9) incremento a nivel nacional del turismo de naturaleza, cultural y de aventura.

Si acentuamos la fortaleza más importante que al igual es que (F6) se encuentra ubicado dentro de dos rutas importantes, la maya y camino real y la promocionamos como tal, mi amenaza más beneficiada, será que se disminuirá el (A2) acceso restringido a fuentes de financiamiento pues habría mayor demanda turística y esto conlleva a inversión en servicios.

Al superar la debilidad que esta (D7) delimitada por la norma 133, estoy minimizando en gran manera mi amenaza (A2) acceso restringido a fuentes de financiamiento, pues, al debilitar las especificaciones de protección ambiental podremos aumentar la inversión en infraestructura que de cierta forma hará de Tziscao un lugar mucho más atractivo. 
Revista de Investigaciones - Universidad del Quindío

\section{ENCUESTAA TURISTAS DEL CENTRO ECOTURISTICO TZISCAO}

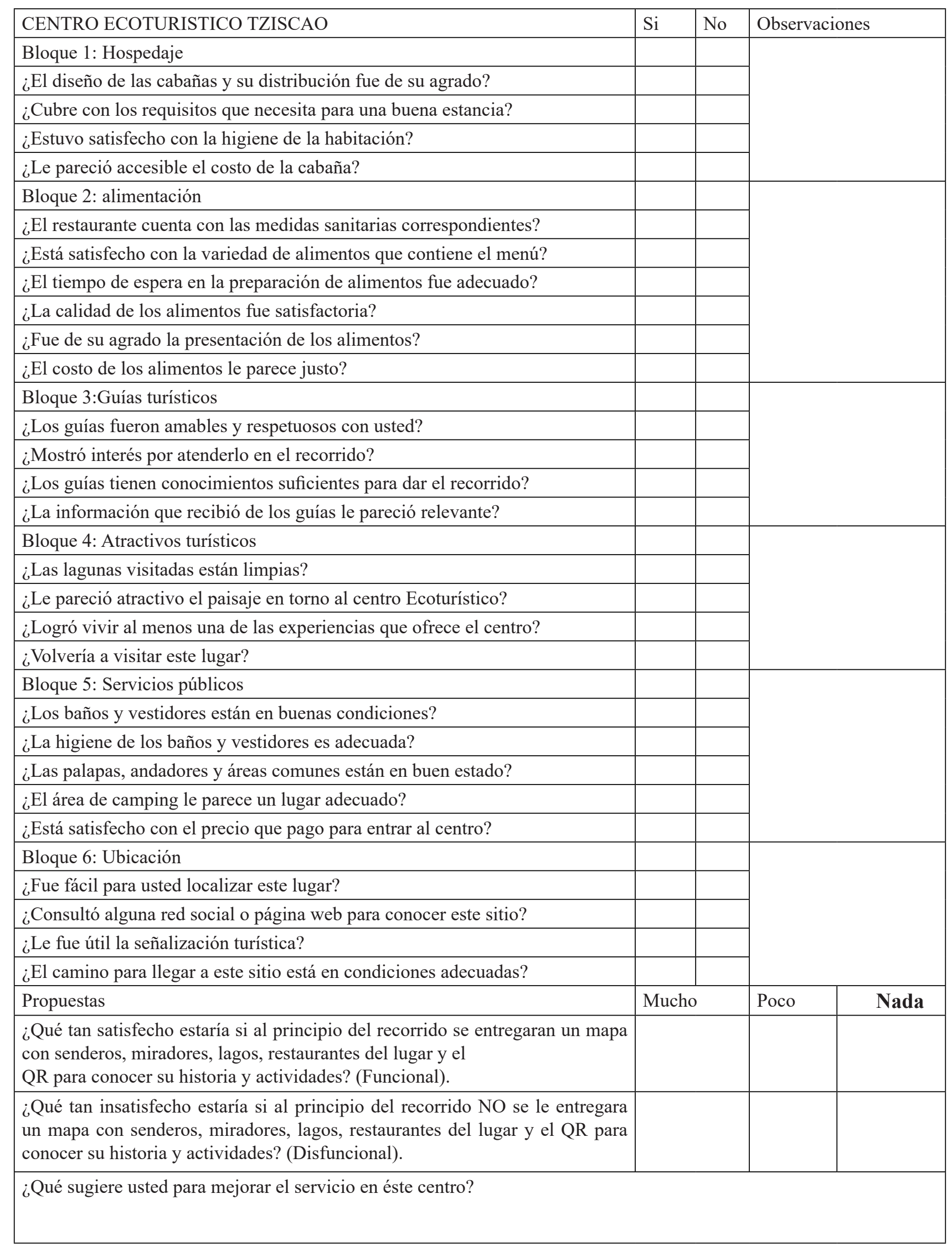




\section{ANÁLISIS DE LAS ENCUESTAS REALIZADAS AL CENTRO.}

\section{Bloque 1: hospedaje}

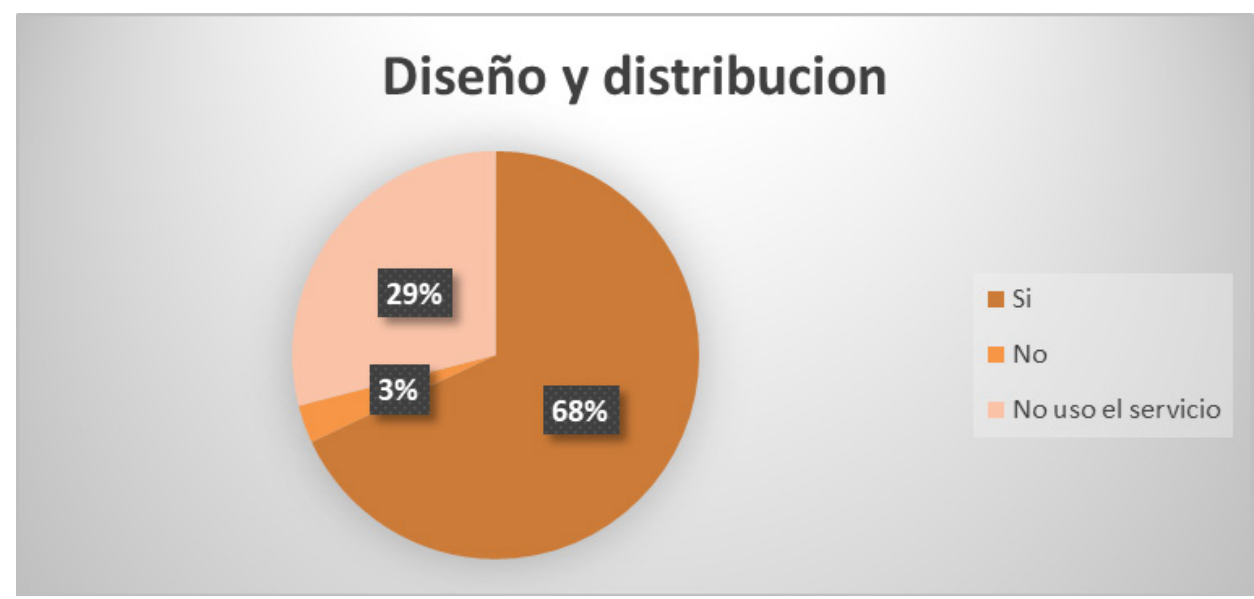

Gráfico 1.1 ¿El diseño de las cabañas y su distribución fue de su agrado?

Interpretación: como puede observarse, de las personas encuestadas el 68\% afirmo que sí, es de su agrado tanto el diseño como la distribución de la cabaña en la que se hospedaron, un 3\% contesto que NO fue de su agrado y el 29\% de los encuestados no se hospedaron en el centro Ecoturístico. (Gráfico $1.1)$.

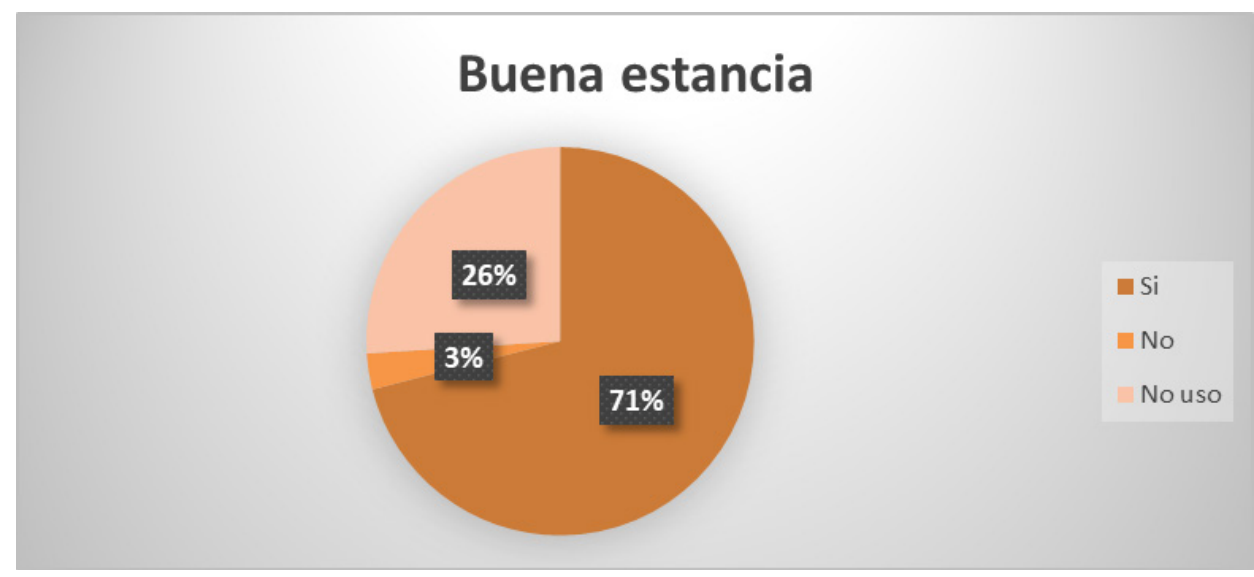

Gráfico 1.2 ¿Cubre con los requisitos que necesita para una buena estancia?

Interpretación: En La gráfica se puede observar que las personas encuestadas, un 71\% afirmó que el hospedaje Si cubre los requisitos para una buena estancia, el 3\% dijo que No y el 26\% No ocupo el servicio. (Gráfico 1.2). 


\section{Higiene}

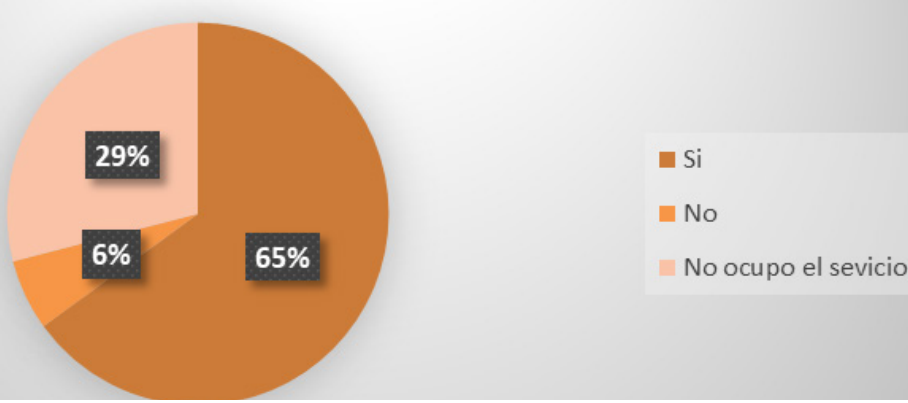

Gráfico 1.3 ¿Estuvo satisfecho con la higiene de la habitación?

Interpretación: se observa en la gráfica que de las personas encuestadas el 65\% respondió que Si está satisfecho con la higiene de la habitación, el 65 dijo que No y el 29\% respondieron que no ocupo el servicio. (Gráfico 1.2).

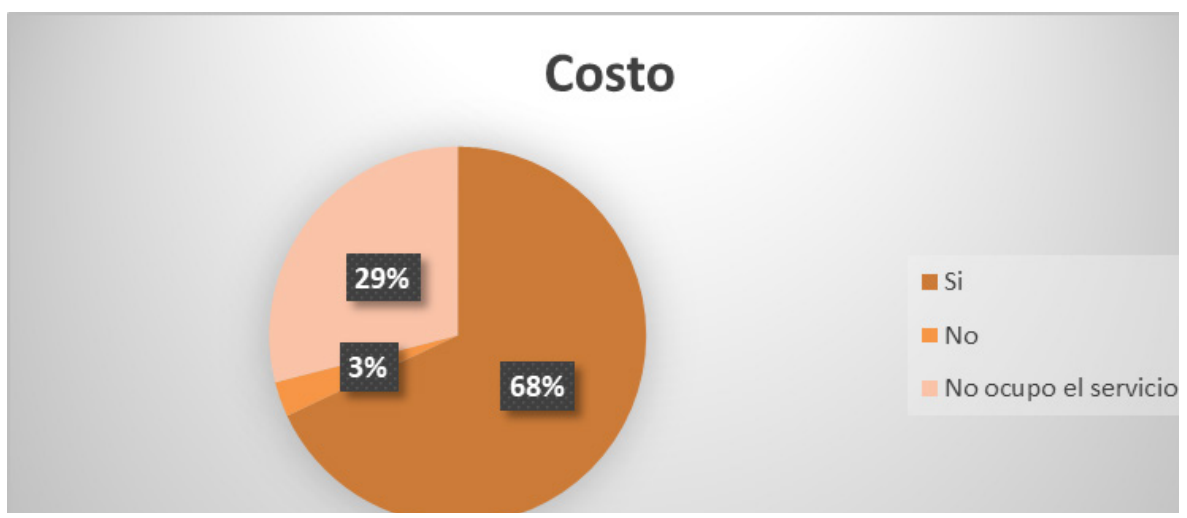

Gráfico 1.4 ¿Le pareció accesible el costo de la cabaña?

Interpretación: en el gráfico se observa que de las personas encuestadas el 68\% dijo que Si está de acuerdo con el costo del hospedaje, el 3\% respondió que No está en acuerdo respecto al costo y el 29\% respondió que no ocuparon el servicio. (Gráfico 1.4).

\section{Bloque 2: alimentación}

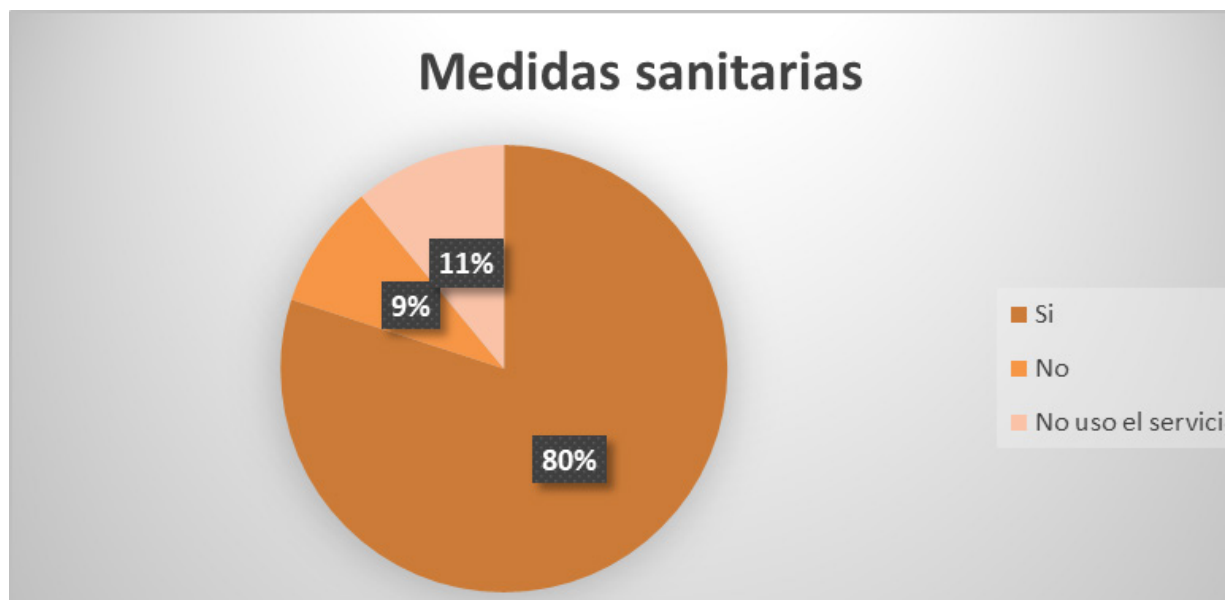

Gráfico 2.1 ¿El restaurante cuenta con las medidas sanitarias correspondientes? 
Interpretación: en el gráfico se observa que el 80\% de las personas encuestadas respondieron que el restaurante Si cuenta con las medidas sanitarias para brindar un buen servicio, el 9\% respondió en que No y el 11\% no consumió nada en el restaurante. (Gráfico 2.1).

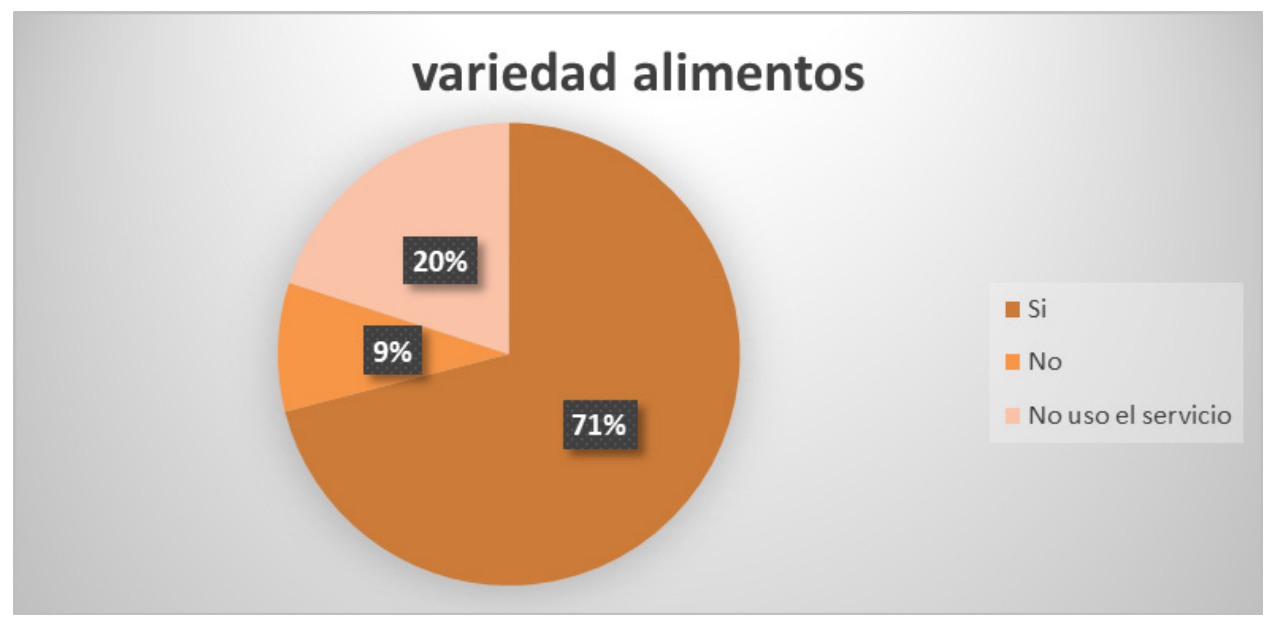

Gráfico 2.2 ¿Está satisfecho con la variedad de alimentos que contiene el menú?

Interpretación: el 71\% de las personas encuestadas respondieron que Si están satisfechos con la variedad de alimentos que contiene el menú, el 9\% respondió que No está satisfecho y el 20\% no consumió alimentos. (Gráfico 2.2).

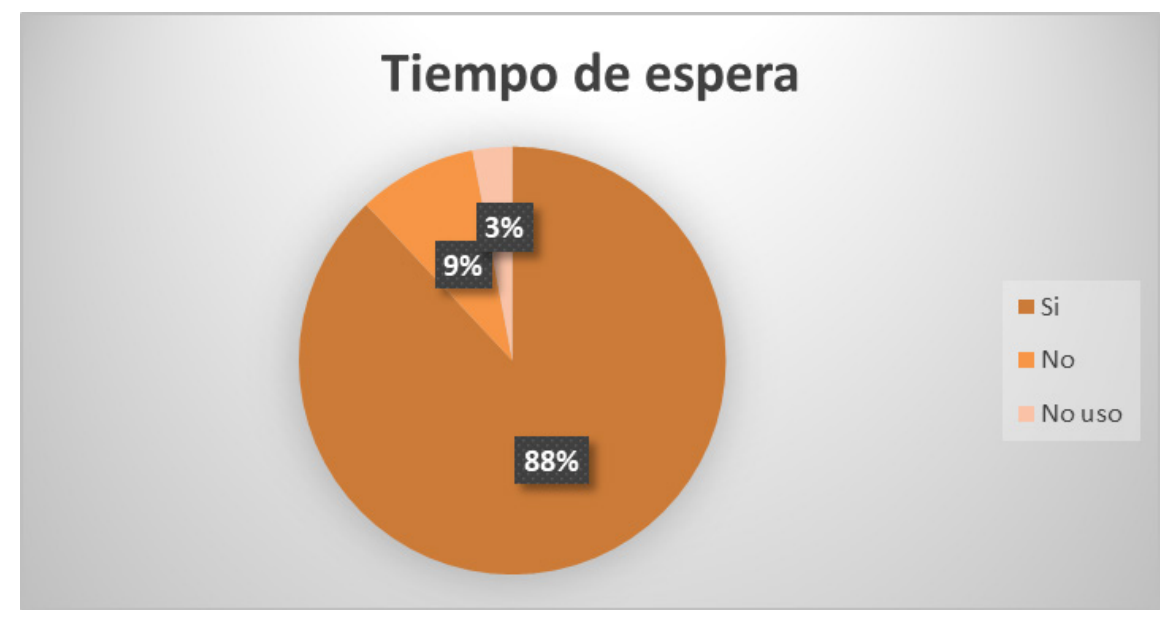

Gráfico 2.3 ¿El tiempo de espera en la preparación de alimentos fue adecuado?

Interpretación: De las personas encuestadas un 88\% respondió que Sí es adecuado el tiempo de espera para la preparación de los alimentos, un 3\% dijo que No es un tiempo adecuado y el 9\% de los encuestados no consumieron algún alimento preparado. (Gráfico 2.3). 


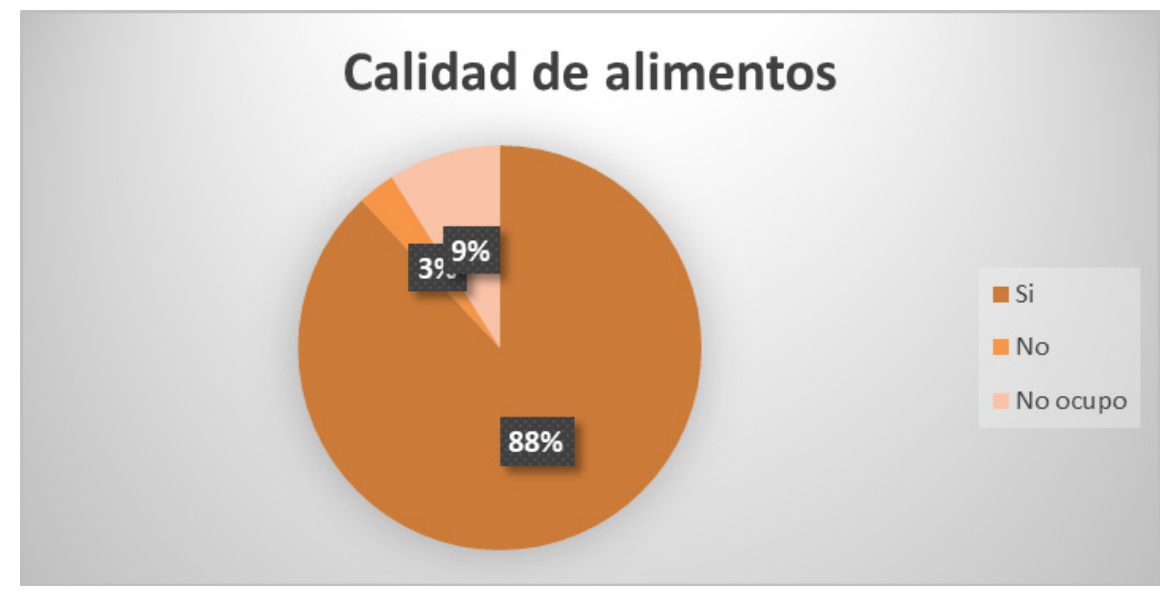

Gráfico 2.4 ¿La calidad de los alimentos fue satisfactoria?

Interpretación: se puede observar en la gráfica que el $88 \%$ de los encuestados respondieron que $\mathrm{Si}$ es satisfactoria la calidad de los alimentos, el 3\% respondió que No y el $9 \%$ No consumieron en el restaurante (Gráfico 2.4).

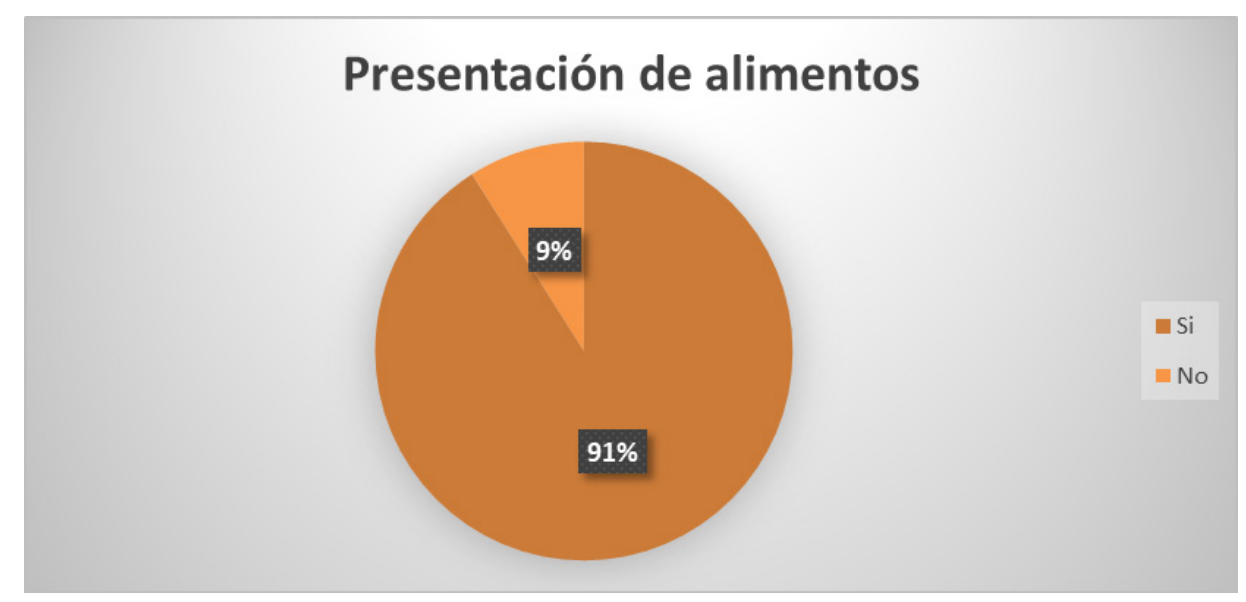

Gráfico 2.5 ¿Fue de su agrado la presentación de los alimentos?

Interpretación: De las personas encuestadas el 91\% respondió que Sí fue de su agrado la presentación de los alimentos consumidos en el restaurante y el $9 \%$ dijo que no fue de su agrado. (Gráfico 2.5).

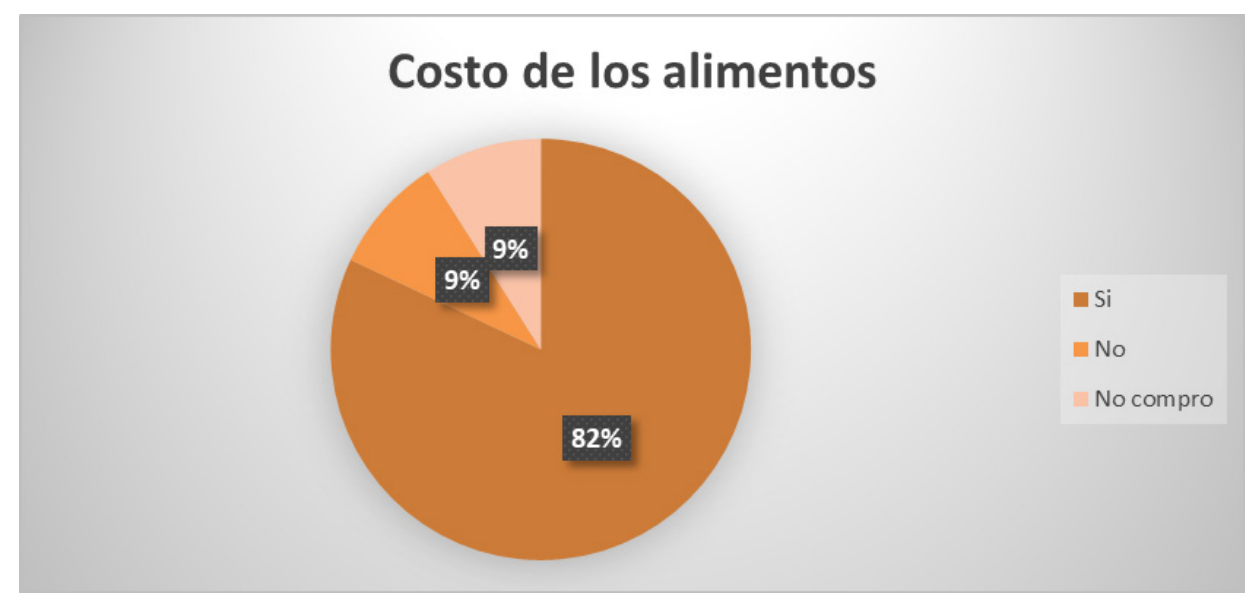

Gráfico 2.6 ¿El costo de los alimentos le parece justo? 
Interpretación: De las personas que consumieron en el restaurante, un $82 \%$ dijo que Si está de acuerdo con el costo de los alimentos, el $9 \%$ dijo no es justo el costo y otro $9 \%$ no compró nada en el restaurante (Gráfico 2.6).

\section{Bloque 3: Guías turísticos}

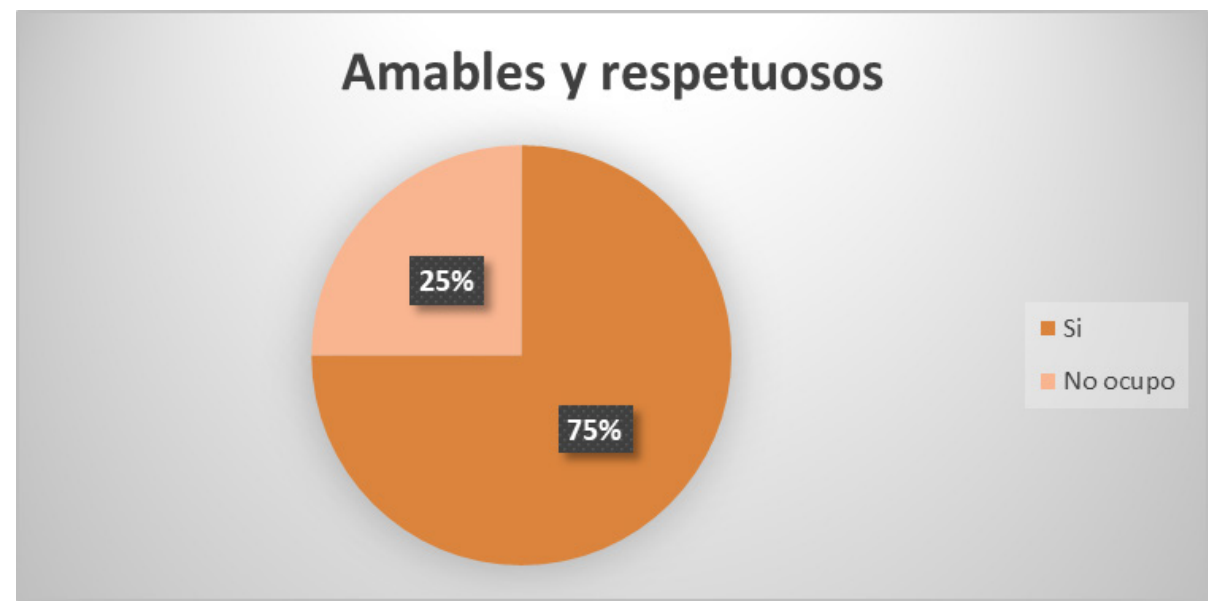

Gráfico 3.1 ¿Los guías fueron amables y respetuosos con usted?

Interpretación: El 75\% de las personas encuestadas respondieron que los Guías Turísticos fueron amables y respetuosos con ellos, al momento de acompañarlos al recorrido y el $25 \%$ No ocupo de Guías Turísticos porque no fue necesario (Gráfico 3.1).

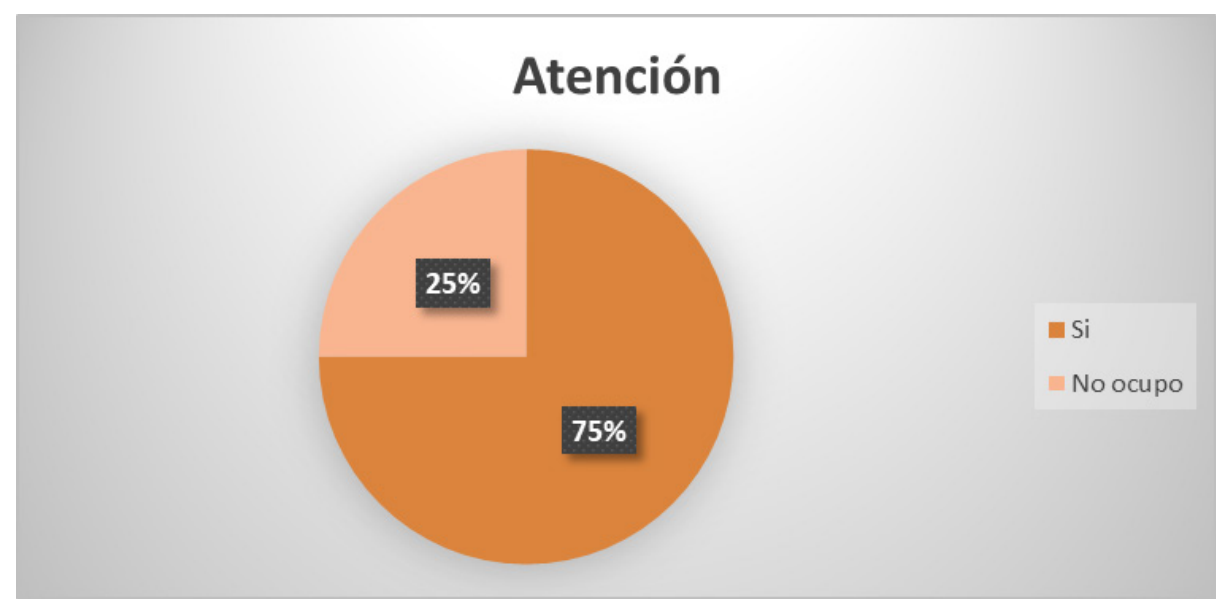

Gráfico 3.2 ¿Mostró interés por atenderlo en el recorrido?

Interpretación: Del 75 \% que adquirió el servicio de Guía Turístico, respondió que el Guía sí mostró interés para atenderlo durante el recorrido y el 25 No ocupo del servicio (Gráfico 3.2). 


\section{Conocimientos suficientes}

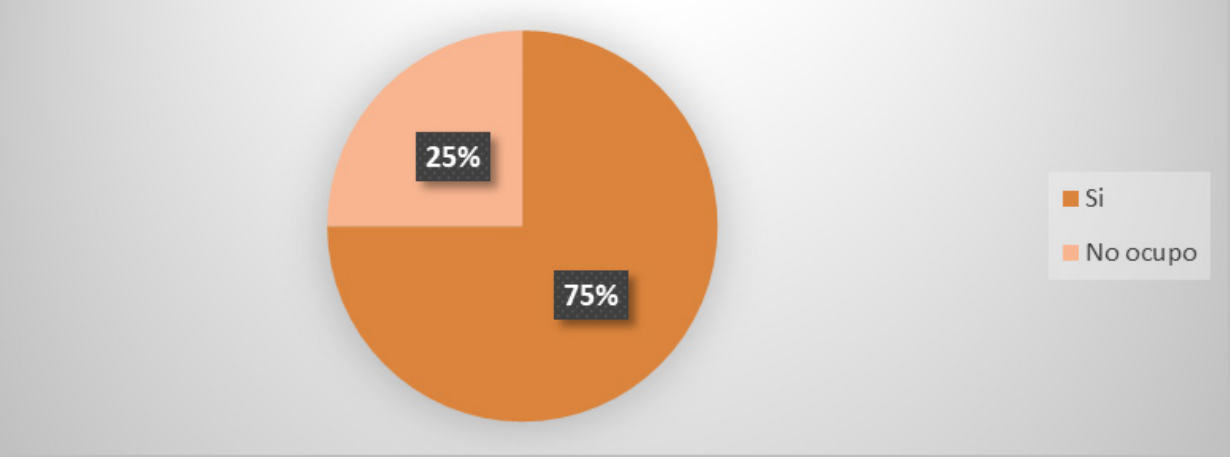

Gráfico 3.3. ¿Los guías tienen conocimientos suficientes para dar el recorrido?

Interpretación: El 75\% de las personas que adquirió Guía dijo que si cuentan con conocimientos suficientes para brindar el servicio dentro del centro Ecoturístico y el otro $25 \%$ No dispuso de Guía (3.3).

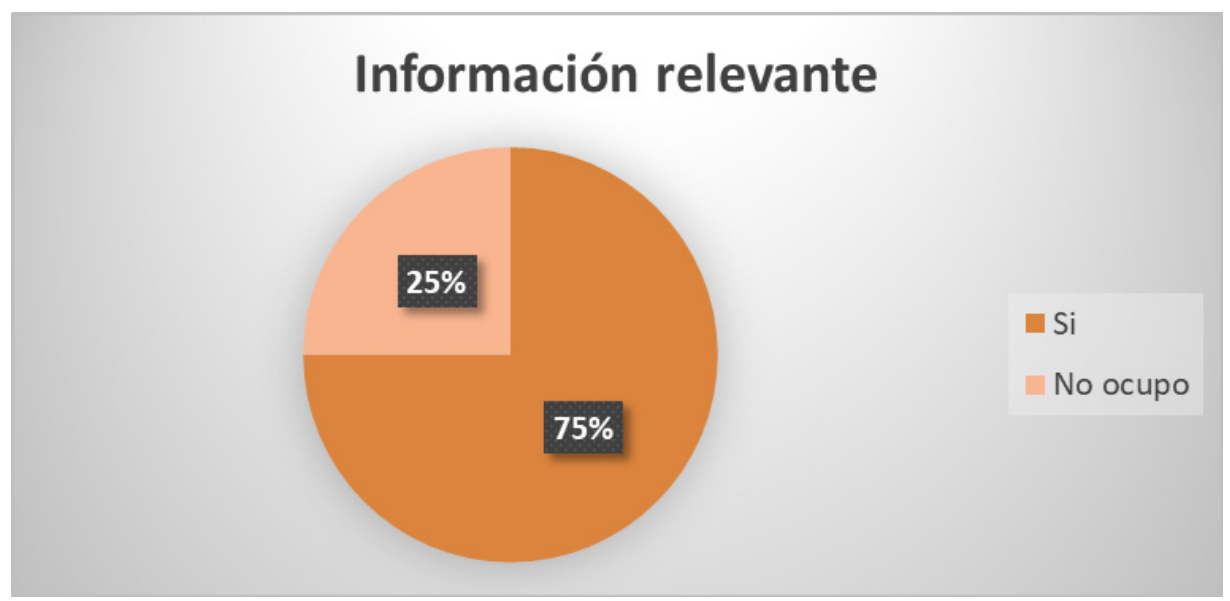

Gráfico 3.4 ¿La información que recibió de los guías le pareció relevante?

Interpretación: El 75\% dijo que la información recibida de parte del guía Si es relevante, el otro 25\% no adquirió el servicio (3.4).

\section{Bloque 4: Atractivos turísticos}

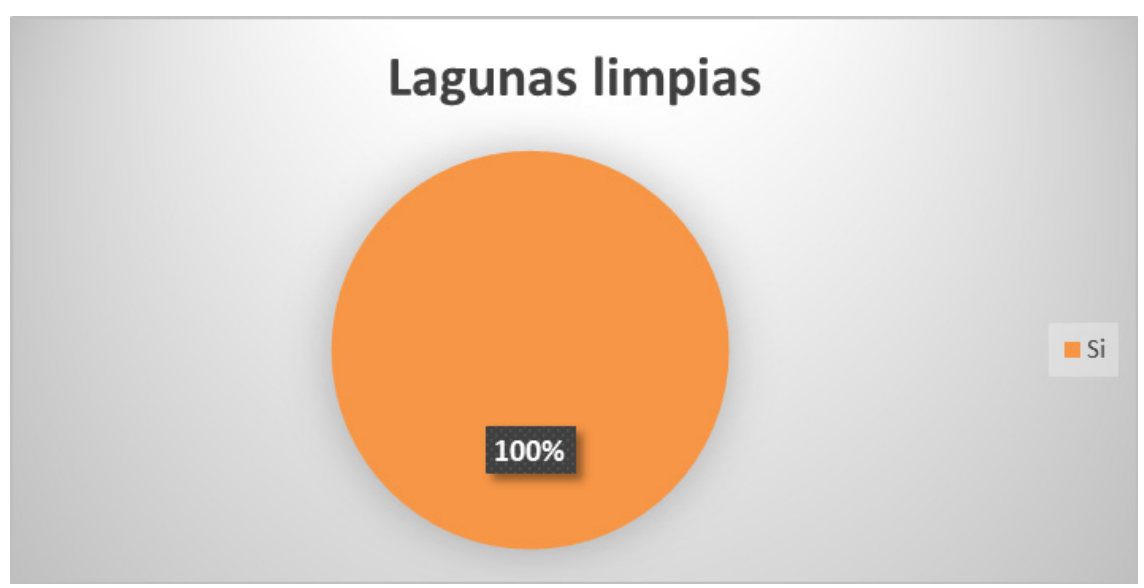

Gráfico 4.1 ¿Las lagunas visitadas están limpias? 
Interpretación: El 100\% de las personas encuestadas respondieron que los lagos visitados Si están limpios (Gráfico 4.1).

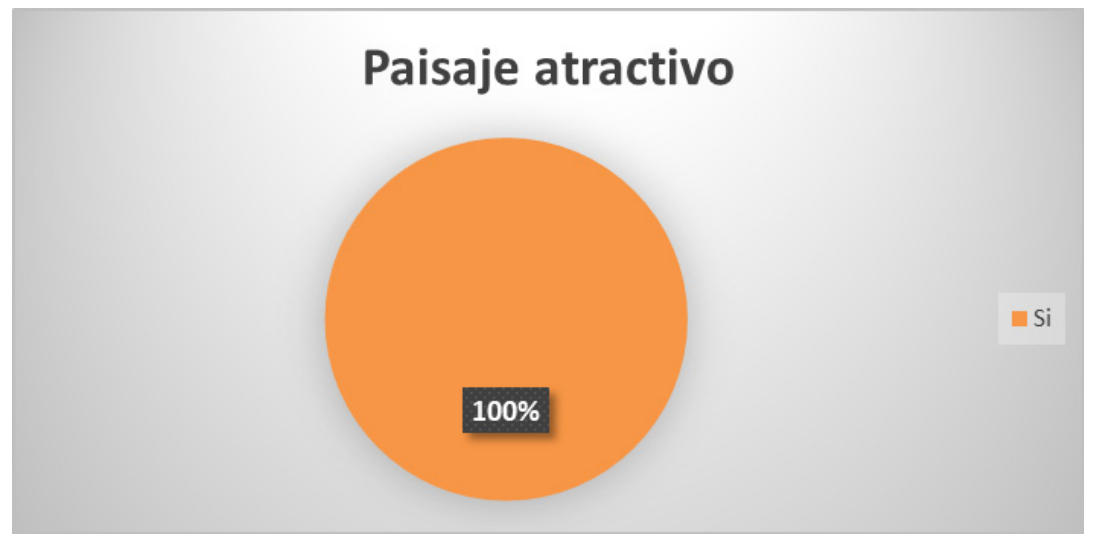

Gráfico 4.2 ¿Le pareció atractivo el paisaje en torno al centro Ecoturístico?

Interpretación: E1 100\% de las personas respondieron que el paisaje Si es atractivo en torno al Centro ecoturístico (Gráfico 4.2).

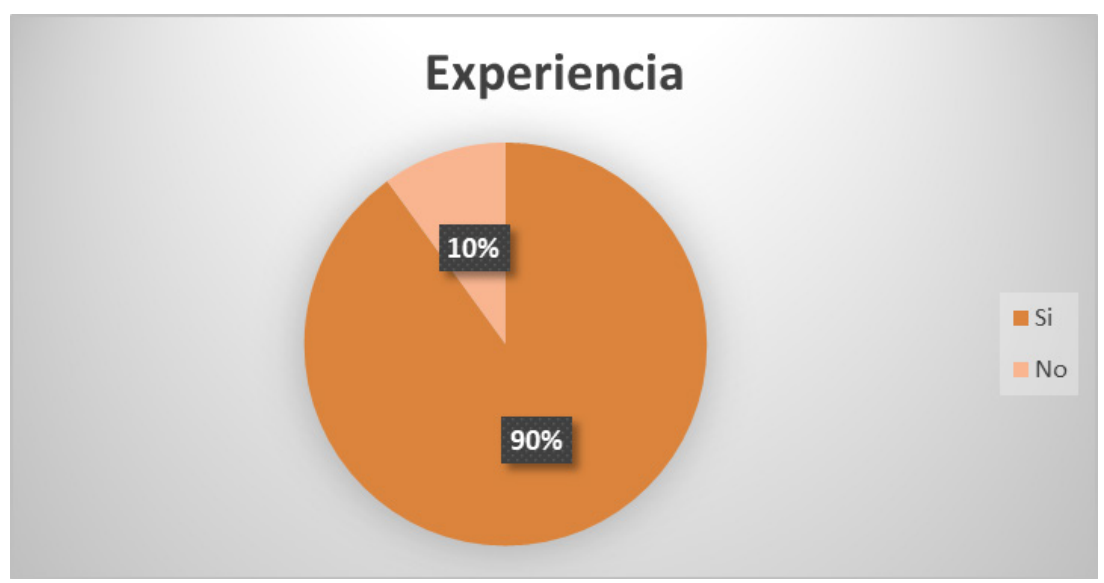

Gráfico 4.3 ¿Logró vivir al menos una de las experiencias que ofrece el centro?

Interpretación: El 90\% de las personas respondieron que Si lograron vivir una de las experiencias que brinda en centro y el 10\% no experimentó alguna aventura (Gráfico 4.3).

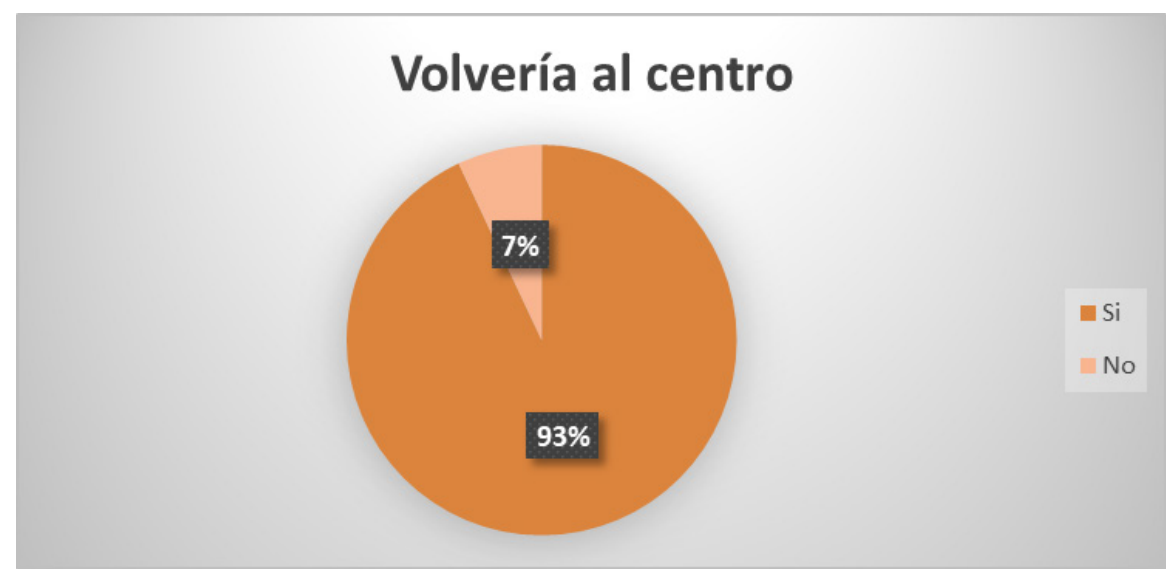

Gráfico 4.4 ¿Volvería a visitar este lugar? 
Interpretación: El 93\% afirmó que Si volvería a visitar éste Centro Ecoturístico, mientras el 7\% dijo que no regresaría Gráfico (4.4).

\section{Bloque 5: Servicios públicos}

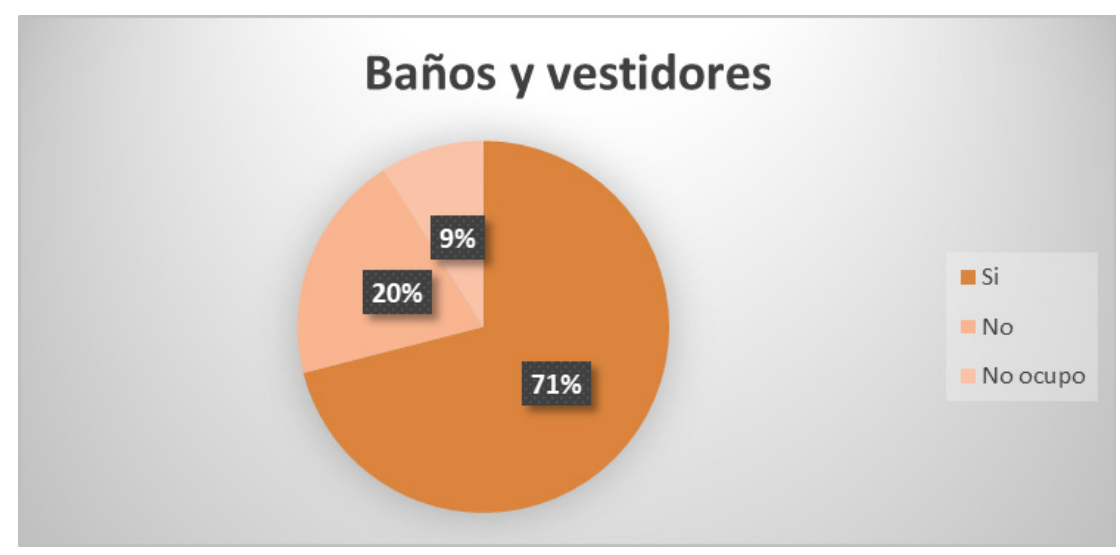

Gráfico 5.1 ¿Los baños y vestidores están en buenas condiciones?

Interpretación: Se puede observar que el 71\% dijo que los baños y vestidores Si están en buenas condiciones, el 20\% respondió que No y el 9\% No ocupo del servicio (Gráfico 5.1).

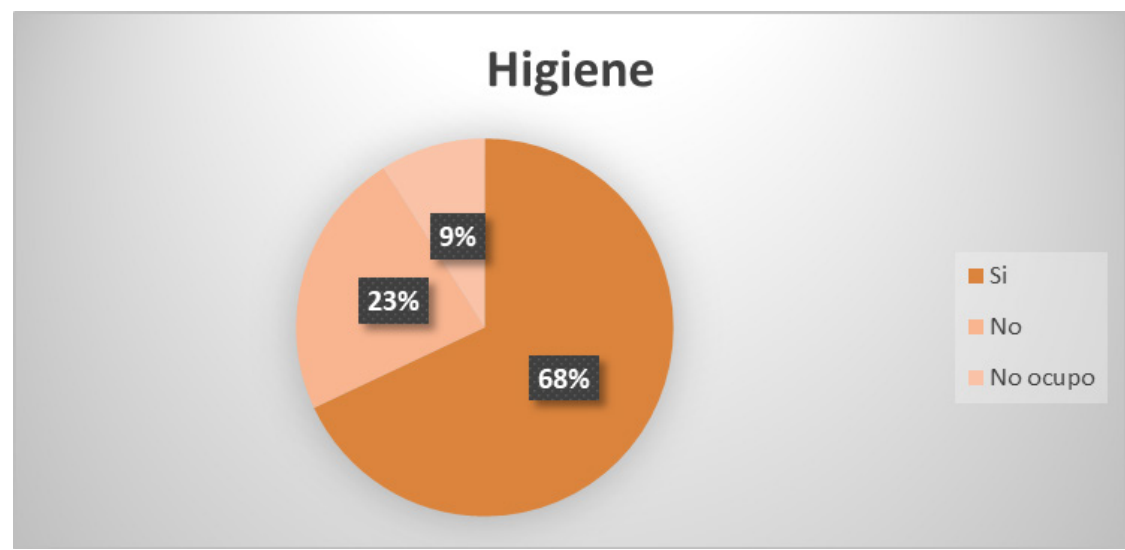

Gráfico 5.2 ¿La higiene de los baños y vestidores es adecuada?

Interpretación: El 68\% respondió que la higiene de los baños y vestidores Si es adecuado, mientras el 23\% dijeron que No y el 9\% No ocupo del servicio (Gráfico 5.2).

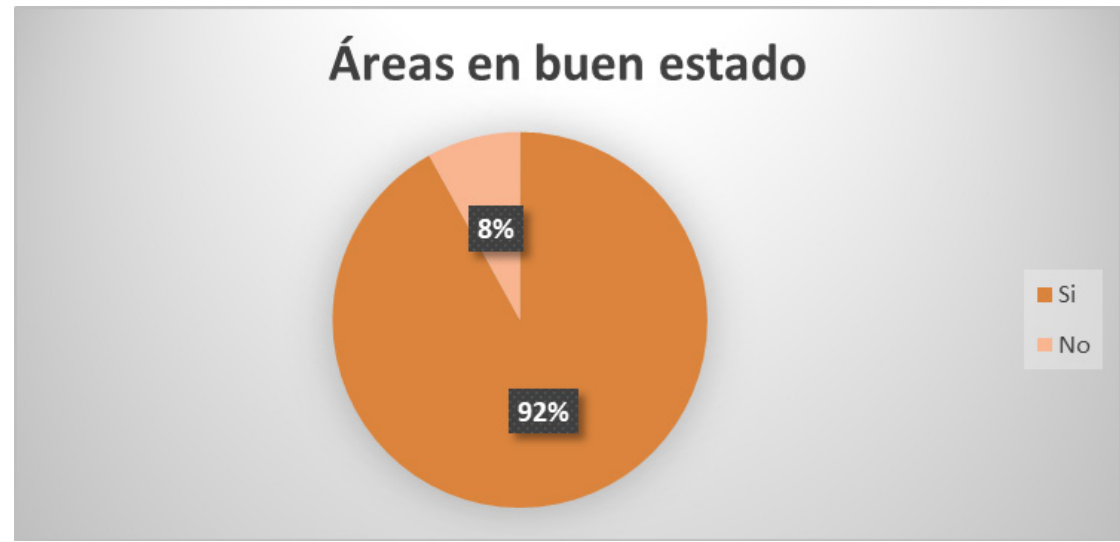

Gráfico 5.3 ¿Las palapas, andadores y áreas comunes están en buen estado? 
Interpretación: El 92\% respondió que las palapas, andadores y áreas comunes Si están en buen estado para poder caminar con confianza y el 8\% dijo que No están en buen estado (Gráfico 5.3).

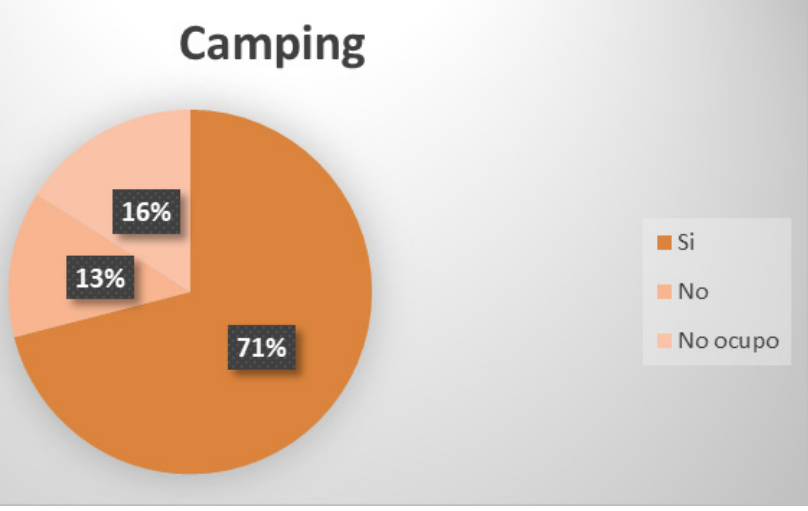

Gráfico 5.4 ¿El área de camping le parece un lugar adecuado?

Interpretación: Para el 71\% de los encuestados respondió que el área de camping es un lugar adecuado, el 13\% dijo que No lo es y el 16\% respondió que no ocupo del servicio por lo cual no sabía que tan bueno es el área. (Gráfico 5.4).

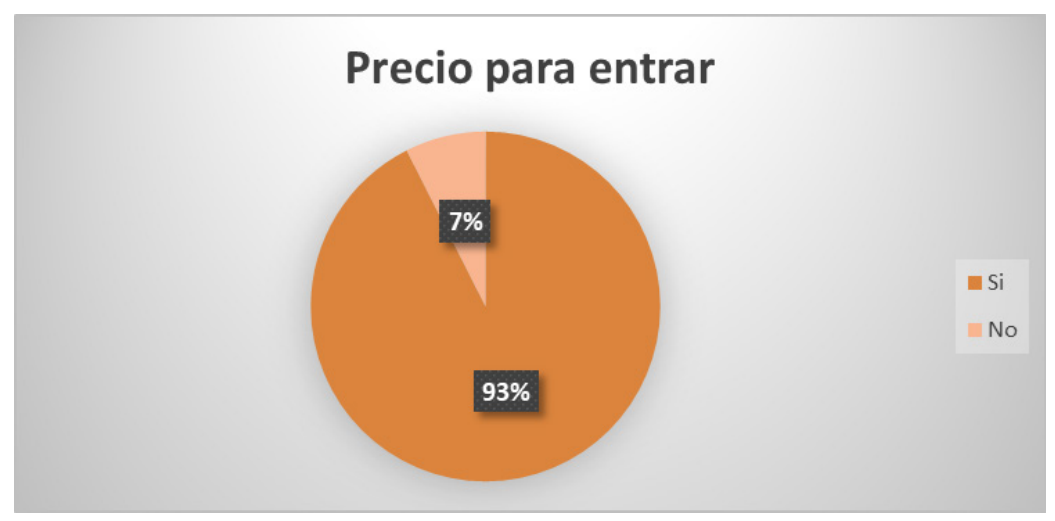

Gráfico 5.5 ¿Está satisfecho con el precio que pago para entrar al centro?

Interpretación: El 93\% respondió que Sí está bien satisfecho con el precio que se paga para entrar al Centro Ecoturístico y solo el 7\% dijo No estar satisfecho (Gráfico 5.5).

\section{Bloque 6: Ubicación}

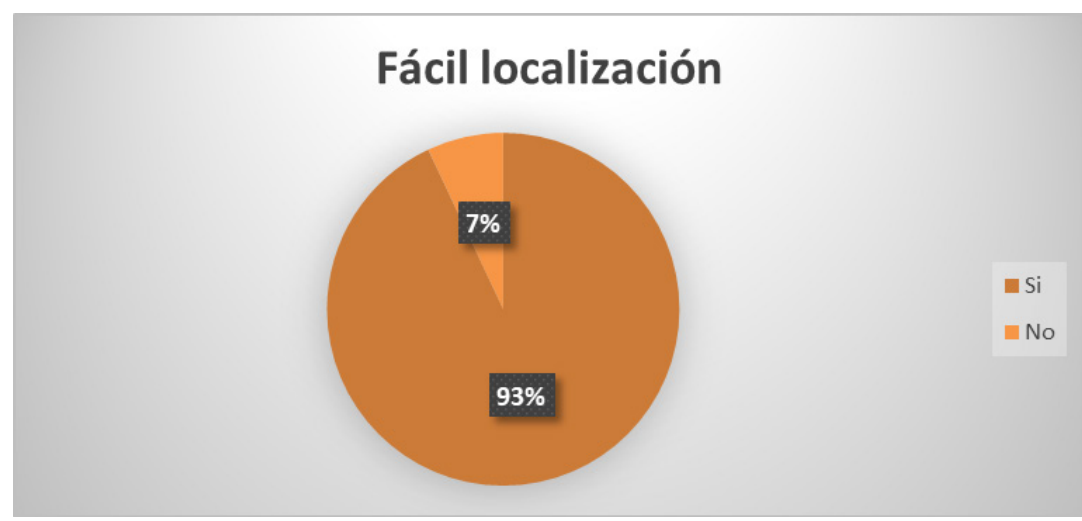

Gráfico 6.1 ¿Fue fácil para usted localizar este lugar? 
Interpretación: Para el 93\% de los encuestados respondió que Sí fue fácil localizar este centro Ecoturístico y el 7\% respondió que sí fue complicado localizar el lugar (Gráfico 6.1).

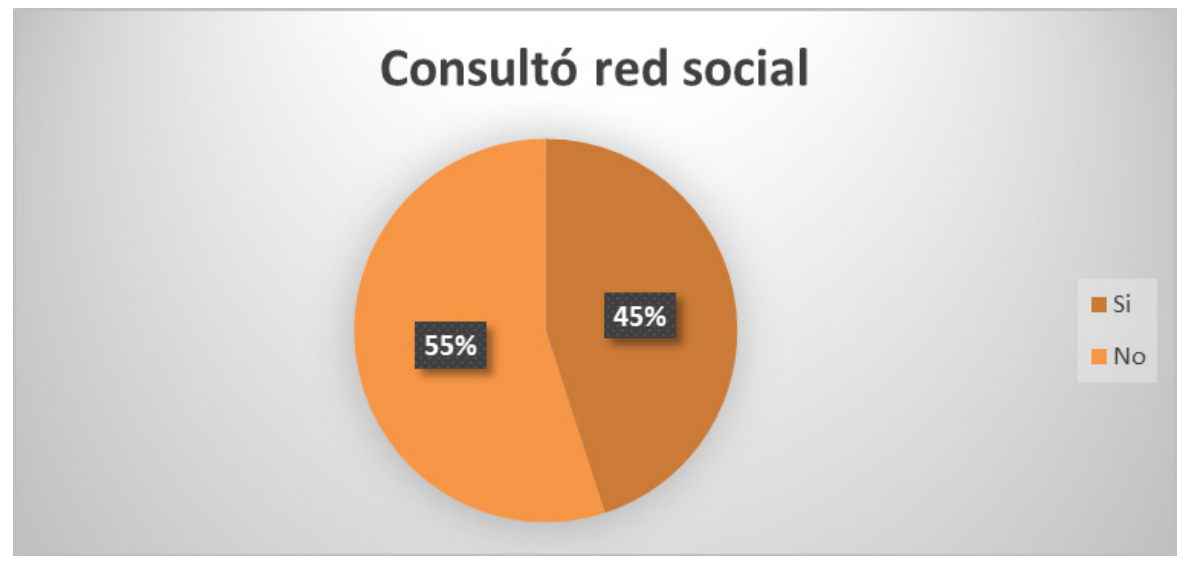

Gráfico 6.2 ¿Consultó alguna red social o página web para conocer este sitio?

Interpretación: El 45\% de las personas respondió que Sí consulto alguna red social para conocer el lugar y el 55\% respondió que No consultó red social porque llegaron por medio de una Operadora Turística.

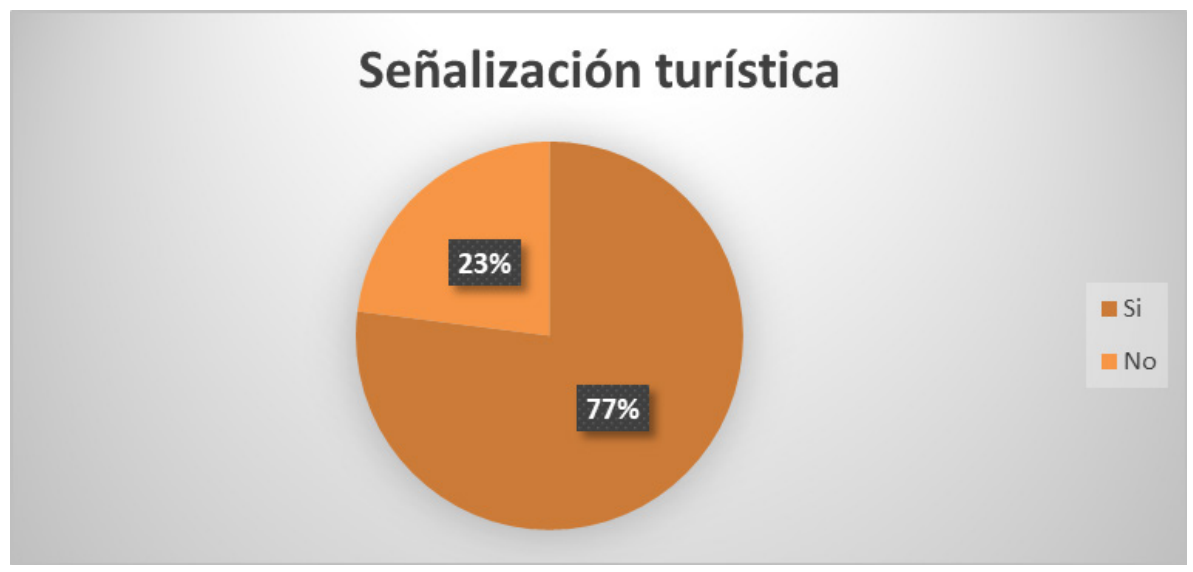

Gráfico 6.3 ¿Le fue útil la señalización turística?

Interpretación: Solo para el $23 \%$ de los encuestados respondió que sí le fue útil la señalización turística y para la Mayoría con porcentaje del 77\% dijo que No fue nada útil la señalización turística, necesita ampliarse porque no se mira fácilmente (Gráfico 6.3).

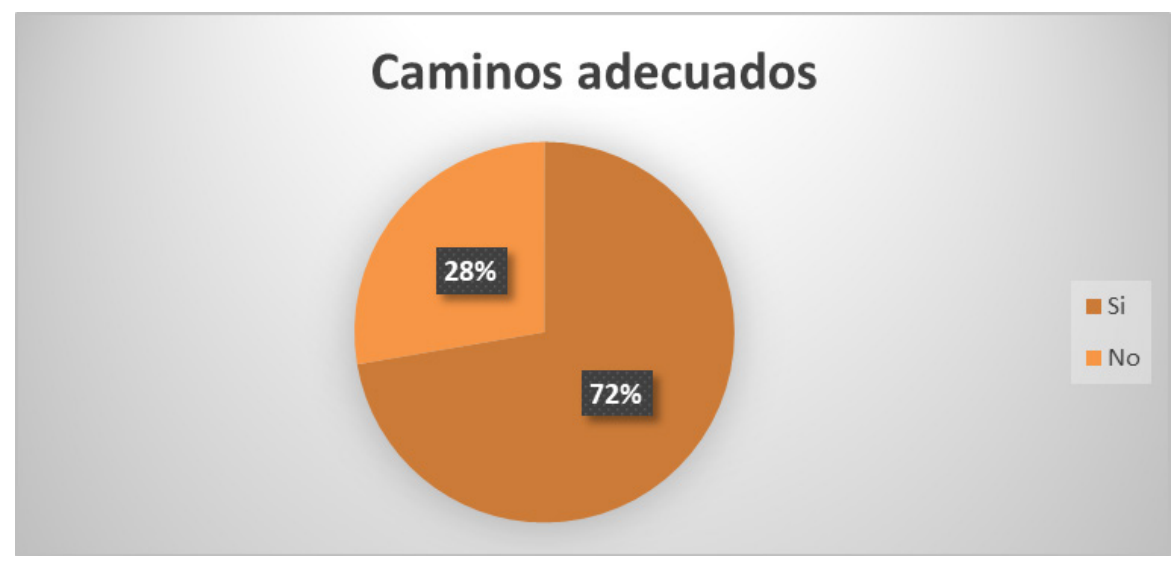

Gráfico 6.4 ¿El camino para llegar a este sitio está en condiciones adecuadas? 
Interpretación: Para el 28\% de las personas encuestadas Si afirmó que los caminos están en buenas condiciones y el 72\% dijo que los caminos No son los adecuados y deben realizarse inversiones para mejorar los caminos para llegar con más facilidad (Gráfico 6.4).

\section{Propuestas}

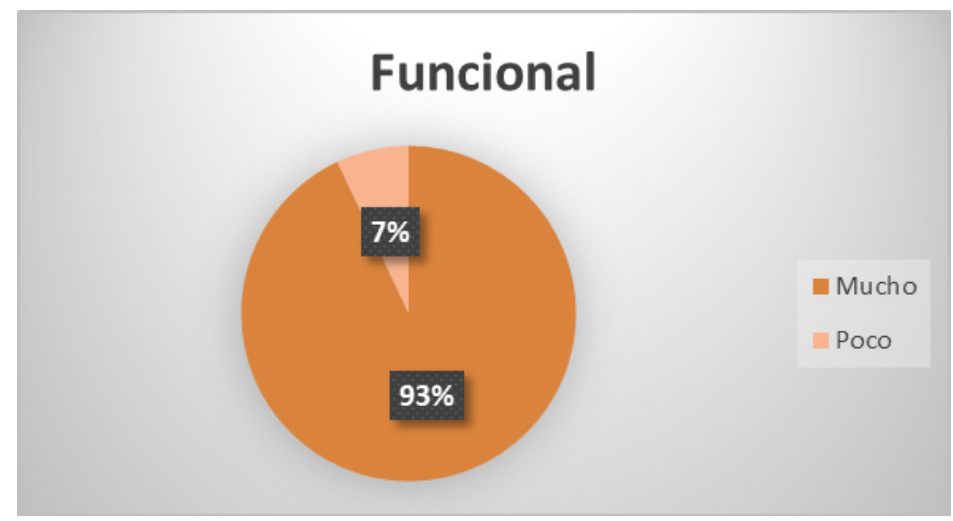

Gráfico 7.1 ¿Qué tan satisfecho estaría si al principio del recorrido se entregaran un mapa con senderos, miradores, lagos, restaurantes del lugar y el QR para conocer su historia y actividades? (Funcional).

Interpretación: E1 93\% Sí estaría muy satisfecho que se entregará un mapa para conocer mejor el Centro Ecoturístico y solo el 7\% dijo que le importaría poco (Gráfico 7.1).

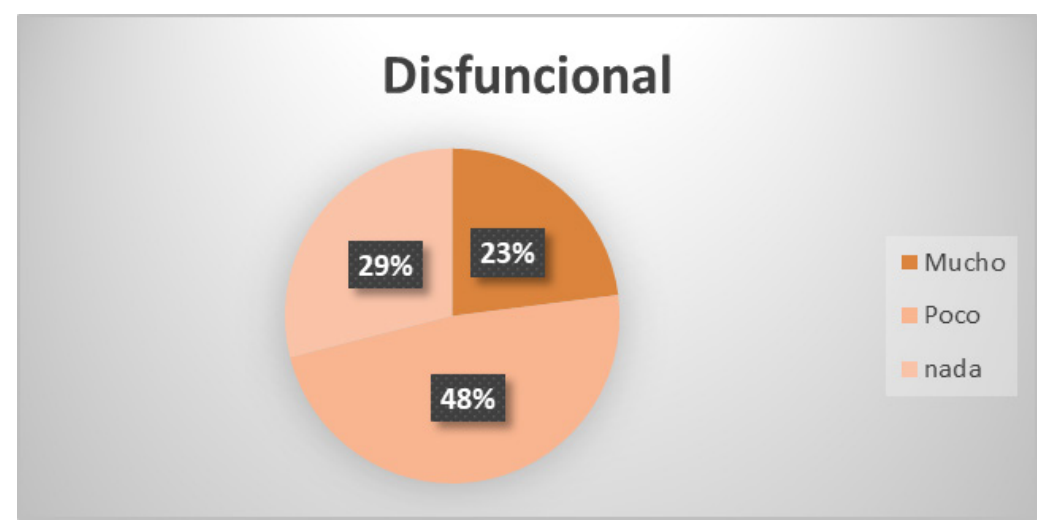

Gráfico 7.2 ¿Qué tan insatisfecho estaría si al principio del recorrido NO se le entregara un mapa con senderos, miradores, lagos, restaurantes del lugar y el QR para conocer su historia y actividades? (Disfuncional).

Interpretación: Solo el 23 \% le importaría mucho que No se entregue nada de mapas para la ubicación y conocimiento del centro, el $48 \%$ estaría muy poco satisfecho y el $29 \%$ estaría nada satisfecho que no se haga (Gráfico 7.2).

\section{PROPUESTAS DE MERCADOTECNIA ESTRATÉGICA PARA LA REACTIVACIÓN ECONÓMICO DEL CENTRO ECOTURÍSTICO TZISCAO EN LA TRINITARIA, CHIAPAS.}

Después de una larga investigación de cada centro y particular del objeto de estudio Tziscao, se ha establecido la situación interna y externa el cual ha permitido conocer sus factores más y menos importantes, se han relacionado de acuerdo a la importancia y el impacto que hay entre sí, se ha 
estudiado el perfil de visitante y su opinión, en base a toda la información recopilada se propone las siguientes estrategias.

1. Promocionar el atractivo en puntos estratégicos como son aeropuertos, terminal de autobuses, en zonas fronterizas, colocando anuncios, carpas y volantes.

2. Asociar al centro con tour operadoras pues es una forma eficiente de acaparar turistas.

3. Desarrollar y promocionar la comercialización de productos elaborados por manos de grupos indígenas del territorio chiapaneco como guatemalteco, estableciendo y consolidando una marca que represente la cultura, historia y riqueza de la región.

4. Diseñar paquetes de servicios para oferta turística de acuerdo a la estación del año, promocionando la gastronomía local, el turismo de aventura y de naturaleza detallando las actividades correspondientes, costo y lugar de hospedaje.

5. Establecer junto al costo de entrada al centro un croquis de recorrido.

6. Para alcanzar la fidelización y recomendación del visitante dependerá de la atención o experiencia que ha vivido en el lugar, por ello es que se propone capacitar a la población sobre la atención, adaptado a las necesidades del visitante, diversificando y adecuando la infraestructura, contenidos y soportes de atención, acogida e información a los distintos segmentos y públicos que nos visitan

7. Fomento de innovación e introducción de nuevas tecnologías y herramientas orientadas a la mejora.

8. Fomentar la cultura de reinversión y de administración.

\section{DISCUSIÓN/CONCLUSIONES}

Se plantearon líneas de acción para reactivar el turismo en el centro ecoturístico Tziscao para lograr el objetivo que se plasmó inicio del proyecto, se realizó un exhausta investigación documental como de campo, por lo cual se diagnosticó el estado actual de cada centro, esto se hizo mediante un análisis interno y externo, en la cual se pudo observar que fortalezas, oportunidades, debilidades y amenazas que tiene el centro, para poder identificar que estrategias emplear. También se realizó un inventario por centro con el fin de tener en documento que productos y servicios ofrece al turista, puesto que es importante determinar que podría estar limitando la visita a estos centros y de ser posible emplear más servicios y productos que sean de interés para los turistas, después de terminar con el inventario se observó lo que tiene y desde punto se generó estrategias para mejoramiento en los servicios ofrecidos.

Continuamente se hizo investigación de campo, con una herramienta muy útil; la aplicación de encuestas físicas, se llevó a cabo para saber la satisfacción de los clientes quienes compran de algún servicio en el centros eco turístico, el resultado de estas encuestas ayudó a generar las propuestas de acción para los centros de la trinitaria.

Entonces se cumplió con los objetivos planteados, ahora se sabe que prefieren los turistas y también lo que nos les gusta y que valoran más.

Ahora se espera que pueda llevar a cabo alguno de las propuestas que se integró en el plan estratégico, para impulsar al turismo.

Una de las propuestas es "Desarrollar y promocionar la comercialización de productos elaborados por manos de grupos indígenas del territorio chiapaneco como guatemalteco, estableciendo y consolidando una marca que represente la cultura, historia y riqueza de la región" se sabe que al turista le gusta tener nuevas experiencias y a muchos no importa lo que cueste, entonces el ofrecer nuevas experiencias 
es bastante atractivo para muchas personas. Con los análisis realizados se observó que en el centro cuenta con mucha riqueza natural que aún falta por explotar.

\section{REFERENCIAS}

1. Antón Álvarez Sousa, G. R. (2008). INNOVACIÓN TURÍSTICA:PERSPECTIVAS TEÓRICAS Y OBJETOS DE ESTUDIO. ROUT, Revista deOcio Y Turismo(1), 19 - 50.

2. Haudnes, J. (1998). Services in Innovation, Innovation in Services, SI4S Final Report. STEP Group Oslo.

3. Plog, S. (1974,). Why destination areas rise and fall in popularity, Cornell Hotel Restaurant and Administration Quaterly.

4. Vas, G. M. (2017). Aplicación de los principios de la planificación estratégica al turismo. Análisis de un proceso de escala regional. (Vol. 56). Granada, España: Cuadernos Geográficos. Recuperado el 02 de Octubre de 2020.

5. Velasco, M. (2016). "Entre el poder y la racionalidad: gobierno del turismo, política turística, planificación turística y gestión pública del turismo".

6. Vera, J. F., López Palomeque, F., \& Marchena, M. J. (2011). Análisis territorial del turismo y planificación de destinos turísticos. Salvador: Valencia: Tirant Lo Blanch. 